\title{
Epigenetic Rules and Darwinian Algorithms
}

\author{
The Adaptive Study of Learning and Development
}

\author{
Richard D. Alexander \\ The University of Michigan, Ann Arbor, Michigan
}

Recent efforts toward a Darwinian psychology of human behavior will profit from taking account of prior investigations of proximate phenomena and adaptive mechanisms conducted within the science of biology, and from realizing that adaptive significance and underlying mechanisms must be investigated in concert. Contrary to some recent arguments, evidence of adaptive design is usually manifested initially and most prominently in the behavior (or other "ultimate" phenotypic expressions) of organisms, human or nonhuman, rather than in underlying psychological, physiological, or developmental mechanisms, which are often obscure, and in any case, as adaptive mechanisms, must be investigated secondarily. The reason is that selection acts most directly on behavior, and on its underlying mechanisms only as they influence the behavior. This is as true for learncd and cultural behaviors as for any others. Adaptive significance of behavior, and evidence of its underlying design, is thus examined only by studying the behavior itself, its complexity, the situations in which it is expressed, and its effects in different situations. Biological mechanisms of any kind cannot even be identified with confidence, or understood, until, at the least, reasonable inferences have been made about their adaptive functions, what they are, as mechanisms, designed by selection to accomplish. Moreover, what appear to be adaptive psychological, physiological, or other mechanisms, may, as with some expressions of behavior, be incidental effects of still other mechanisms that are adaptive.

Adaptation is not restricted to situations in which genes program specifically for particular behavioral alternatives: natural selection of alternative alleles may also yield abilities and tendencies to engage in conditional strategies, to assess costs and benefits in directly or indirectly reproductive terms. In humans, such cost-benefit assessments may be conducted entirely through mental scenario-building, or even through absorbing and judging the mental scenarios of others, without either admission or cognizance of the reproductive significance of the assessment. The goals actually sought may be secondary, tertiary, or even more distantly removed correlates of reproductive success (e.g., status or reputation, which may correlate with power, which may correlate with wealth, which may correlate with access to the resources of reproduction); reproductive success itself may be a concept alien to the actor's conscious motivations, even denied vehemently as a goal. In learned and cultural behaviors, selection has to be not only

Received April 20, 1990; revised April 30, 1990. Address reprint requests to: Richard D. Alexander, Muscum of Zoology, University of Michigan, Ann Arbor, Michigan 48109. 
for the ability to learn but for its patterning, such as for the machinery enabling development of the ability to learn to make appropriate (cultural) decisions.

Kin recognition is reviewed as the most prominent example of a set of extensively studied adaptive mechanisms involving learning, and as a central problem with respect to adaptiveness in social behavior. Arguments that the adaptive mechanisms collected under the concept of learning evolve as special, rather than general-purpose devices, raise provocative questions about the evolution of ontogenetic and physiological preparation to deal with environmental novelty, especially in complex social interactions. Evolution of the human psyche, especially its conscious aspects, is briefly discussed as a problem in understanding the history of sociality. It is argued that the principal environment of natural selection leading to the modern human psyche was social, and that on this account the environment of human behavior has not changed as much since the Pleistocene as is often assumed.

KEY WORDS: Adaptive design; Consciousness; Epigenesis; Kin recognition: Learning.

\section{INTRODUCTION}

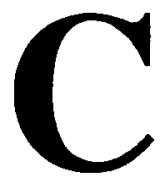

harles $\mathrm{H}$. Waddington (1956) may have been the first to use the Aristotelian term "epigenesis" in the modern sense, referring to all events by which the zygote is transformed into an organism and then continues to function throughout life; literally, whatever is built on the genetic materials. Lumsden and Wilson (1981) coined the phrase "epigenetic rules" to focus attention on elucidating laws, principles, or mechanisms that underlie adaptive phenotypic outcomes. Cosmides and Tooby (1987) used the more explicity adaptive term "Darwinian algorithms" for the same phenomena. Rozin (1976) called them "adaptive specializations, " and Johnston (1982b) used the term "special purpose epigenetic systems." In each case the authors were trying to generate a view of ontogeny, physiology, and learning-all the events of somatic and reproductive cffort that underlie adaptive outcomes-which makes explicit the assumption that they have been designed by natural selection as mechanisms whereby the organism tends to maximize its inclusive fitness (Hamilton, 1964) in the environments of history.

All of these authors were also trying to generate an evolutionary approach to psychology, or an evolutionary psychology (also see Ghiselin, 1973; Johnston, 1982a; Gould, 1982, 1986; Barkow, 1984, 1988; Tooby, 1985; Tooby and Cosmides, 1988; Cosmides and Tooby, 1988; Symons, 1987, 1988). They were trying to apply Darwinian arguments to the proximate mechanisms of human and animal behavior. In this effort they follow Williams (1966), who, in developing the modern view of evolutionary adaptation, argued extensively for the search for design in the mechanisms underlying adaptation and evolved function: "One should never imply that an effect is a function unless he can show that it is produced by design and not by happenstance"' (p. 261).

These various authors also seek to bridge what Waddington called the 
"great gap in biology," the chasm that separates the study of adaptive phenotypic outcomes as the "ultimate" causes of the evolutionary biologist from, eventually, knowledge of the genetic materials and their primary products. They are trying to discover a manageable set of generalizations that will help connect the organism to the myriad of underlying genetic and environmental influences that created it, that will describe the makeup and history of underlying traits of organisms as the "proximate" causes or mechanisms of adaptive phenotypic outcomes. There is irony in the fact that many of these pioneering efforts are being initiated to help analyze human behavior, and to change a social science that has long been too independent of biology. Although efforts by behavioral biologists to develop learning and other ontogenetic models to explain the behavior of nonhuman organisms are more extensive than seems generally appreciated (for reviews, see Rozin, 1976; Johnston, 1982a, b; Gould, 1982, 1986; Marler and Terrace, 1984; Holmes and Sherman, 1983; Sherman and Holmes, 1985; Alcock, 1989), the parts of the biological sciences concerned with ontogeny, physiology, and related topics (often called "organismic" biology today) have generally failed to view epigenesis as a problem in adaptive (reproductive) design. To a certain extent, one might say that psychology has developed viewing the human organisms as a "happiness" (or pleasure) machine, whereas developmental and physiological biology has tended to think of organisms as "survival" machines. Evolutionary biology, on the other hand, stipulates that unless organisms are most appropriately viewed as reproductive machines, its basic postulates are wrong. ${ }^{1}$

Nevertheless, as I shall show, for what is now being called Darwinian psychology to ignore the long history within biology of extensive study of the underlying mechanisms of behavior-studies that in some cases have focused on evolutionary adaptiveness for more than two decades (e.g., kin recognition: see later and Sherman and Holmes, 1985; Fletcher and Michener, 1987) would simply be a new way for human-oriented scientists to neglect information of central significance to their projects. There can be no doubt that all of the aforementioned authors, although they often do not cite one another, are discussing the same set of problems. All epigenetic rules are Darwinian algorithms and all Darwinian algorithms are epigenetic rules. Every ontogenetic sequence includes physiological mechanisms and every physiological mechanism is part of an ontogenetic sequence. It is misleading to argue that the focus should be on underlying mechanisms of

\footnotetext{
${ }^{1}$ One reader argued that my characterization of psychology as viewing the human organism as a happiness machine is wrong, that psychology is better described as viewing humans as information-processing machines, or computer-like. Such a view, however, cannot evade the problem of why some kinds of information are accepted, others rejected; why some kinds of information are sought and savored, others avoided or forgotten. Any science that stops short of seeking ultimate functions (the organismic biologists" "survival" qualifies here, even if incomplete or wrong) is stuck with labels like "happiness" or "pleasure" for the mechanisms that result in the seeking and repeating of some outcomes and the rejection or avoidance of others. Unlike computers, organisms have no possibility of being viewed as neutral with respect to the selection of information to process.
} 
behavior rather than on the behavior itself; to imply that mechanisms can (ought to) be studied independent of, or prior to, observations of behavioral outcomes and hypotheses concerning adaptive significance (what such mechanisms are designed to do); and to ignore the fact that complexity alone-in behavior as well as its proximate mechanisms-indicates evolutionary (adaptive) design (Williams, 1966), even when the question "design for what?" has not yet been answered (cf. Symons, 1987, 1988). ${ }^{2}$ To maintain progress in the understanding of human behavior, information about a) the historical and reproductive significance of specific acts of behavior and b) their underlying morphological, physiological, and developmental designs must continually be played against one another; neither can be ignored. We must learn how to do this, and remind ourselves to do it. To do it best we must combine contributions from all relevant disciplines.

This issue is not trivial, for it involves everyone's concepts of how changes in genes might result in changes in the behavior of humans during evolution, and in what fashions or to what extents those changes may legitimately be said to be products of evolution by natural selection. This is the only route to understanding development, physiology, and morphologythe phenotype, the proximate mechanisms of behavior, learning, and all of

\footnotetext{
2 A reader questioned this statement, referring to Gould and Lewontin (1979), and noting that "complex structures, like the spandrels of San Marco, can be epiphenomenal. Thus, you must also demonstrate function ..." But spandrels are not in themselves complex; they are simply the spaces between arches. The decorations and other modifications of spandrels are complex. Gould and Lewontin carefully avoided saying that the complex uses of spandrels are not functional. Instead, they said that the complex appearance of what has been placed inside spandrels might cause us to use spandrels as "starting points" in the analysis of function, presumably (in our ignorance or naivete) of arches or ceilings or even cathedrals. I don't think people, even ardent adaptationists, are typically so naive, and I am unable to inagine what is wrong with starting with the decorations of spandrels in understanding the function of those decorations, which is what adaptationists do with the traits of living creatures. All traits (and functions) of living creatures are epiphenomenal, in the sense that they represent modifications of some preexisting condition-a derivation from last year's model. Evolution is an endless succession of such epiphenomenalities. Selection, after all, can only operate on last year's model, regardless of what last year's model did or where it came from. In this sense we cannot examine any aspects of living creatures except as epiphenomena. As soon as selection starts changing and complexifying traits, however, they automatically cease being merely epiphenomena. Even Gould and Lewontin admit that selection is the principal guiding force of evolution, so this kind of change is what tends to happen to every instance of epiphenomenality-every trait that persists. Ihat is why it is parsimonıous to assume that complexity is sufficient evidence of a background of selection-evidence that the trait under consideration is produced by either direct or indirect selective action-just as the complexity of what has been done with the spandrels of San Marco is evidence of functionality, and therefore not only an adequate starting point for the understanding of its own significance but the only logical starting point. Moreover, cathedrals and arches and spandrels appear to be the worst possible example for Gould and Lewotin's insistence that it is inept to explore functions of the parts (spandrels, traits) of larger phenomena (cathedrals, organisms). This particular tirade of Gould and Lewontin against the investigation of adaptiveness has always seemed to me a wonderful recipe for the confusion of reasons for origins of traits and reasons for their maintenance and elaboration; and in my opinion their subsequent arguments on many aspects of living creatures continue to demonstrate that they suffer from precisely this kind of confusion (thus, S. J. Gould, 1987, argues that the clitoris of the human female is probably functionless because it originated as a homologue of the male penis, and S. J. Gould, 1981, suggests that the enlarged genitalia of the female spotted hyena are probably functionless herause this condition correlates with an increased titer of testosterone in females; etc. (See Alcock, 1987; Sherman, 1988; and see West Eberhard, 1987, for a sophisticated analysis of the relationship of origins and functions in social behavior).
} 
the so-called "psychological" design features emphasized by recent authors. This issue is of such importance that numerous books and entire issues of journals have been devoted to it. I think misunderstandings about the ontogeny of behavior in relation to its selective background underlie a major part of the hostility toward approaches to human behavior from the discipline of biology. Moreover, it has recently become obvious that even the most sophisticated investigators in the field disagree about proper applications of the concept of evolved adaptiveness to human activities and the relationship of genes to behavioral expression, e.g., see later, Sherman (1987), Symons (1988), Dawkins (1982), and Betzig (1989). ${ }^{3}$

\section{ADAPTIVENESS AND ADAPTIVE DESIGN}

One difference between behaviorists and physiological and developmental biologists who examine proximate phenomena is their starting points. Behaviorists begin with the need to postulate or model a particular sort of hypothetical physiological or ontogenetic underpinning, or background, for their behavioral findings; they tend to work backward from the behavioral expression itself, and are more likely to engage the question of ultimacy (reproductive significance) in their theorizing. So-called organismic (actually, suborganismic) biologists more frequently begin with an observable physiological or other phenomenon before them, and they are usually in a

\footnotetext{
${ }^{3}$ A good example of the kind of misunderstanding and oversimplification that $I$ refer to is the notion that one ought to expect that "a gene" should be locatable that would cause a particular behavior. I see this view as an extension of equally naive views about behavioral expressions being "heritable" if they are to be viewed as products of natural selection (see Appendix). Anyone who considers for a moment Dobzhansky's (1961) admonition that "Heredity is particulate but development is unitary" will understand that observed (and "selectable") behaviors (behavioral differences) are not likely to be manufactured by single alleles. Individual genetic changes are more likely to lead to minor changes in potential ranges of behavioral expressions; and each of these will immediately be subject to (even rapid) changes as a result of additional genetic changes until the manner in which any or all previous individual genetic changes affected (affect!) the behavior become complex and obscured in the developmental pattern. This need not render the behavior immune to selection. Tierney (1986) makes this same point, as a neurophysiologist: ". . . specific genes do not control specific events in normal nervous system development. There are not one-to-one correspondences between genes and neural structures, but rather many-to-many relationships, with each developmental stage guided by epigenetic information (Jacobson, 1978). . . . mutations that alter behavior are not in and of themselves 'compelling evidence' that a given behavior is canalized, because the performance of learned behaviors can also be disrupted by mutations. . . . all identified single-gene behavioral mutations are deleterious, they disrupt the development of the nervous system in complex and sometimes obscure fashions. There is no unequivocal evidence that single genes can program adaptive, canalized behavior." (Also see Edelman, 1987 p. 342). This is precisely the condition that would be realized if my own statement (made independently) is correct. In considering all of Tierney's arguments (especially those about learning being ancestral and innateness or "canalization" bcing derived), however, I think it is important to distinguish between neuronal variability that represents noise (imprecision in the face of epigenetic fluctuations from other sources) and flexibilities in neuronal behavior for which there is good reason to assume a history of selection (i.e., evolved adaptiveness). The usefulness of this distinction, particularly in attempting to understanding the behavior of neurones, emphasizes the importance to all biologists of engaging ultimate questions of functions.
} 
position to carry out some analysis without being concerned with the ultimate function of particular neuromuscular or other kind of units available to them. This difference may be responsible for a (probably widespread) attitude expressed to me by a prominent neurophysiologist who said, "For my work, evolution is just a frill."

Yet, the very term "mechanism" demands an understanding of raison d'etre, and, as Cosmides and Tooby (1987, p. 285) point out, "It is nearly impossible to discover how a psychological mechanism processes information unless one knows what its function is, what it was 'designed' or selected to do"' (see also, Rozin, 1976; Johnston, 1982a, b; Gould, 1986). Moreover, it is hardly debatable that organic evolution has been guided principally by natural selection, a process tending to preserve and elaborate traits of individuals that contribute eventually to their genetic reproduction (Williams, 1966; Dawkins, 1976, 1982, 1987; Alexander, 1979, 1987; Maynard Smith, 1986).

A serious problem faced by evolutionary psychologists seeking to elucidate and generalize underlying mechanisms of behavior, then, is that they must start in ignorance of the kinds of specific devices that organismic biologists analyze, just as those biologists start in ignorance of the ultimate function of the devices they can observe more or less directly. Even when the most straightforward kind of behavior is being analyzed, it is often difficult to develop statements about underlying mechanisms with sufficient specificity to be useful. Speaking of kin recognition mechanisms, Waldman et al. (1988) note that "At present, templates are more difficult to study than labels-indeed, as in studies of bird songs, they remain hypothetical constructs, describing features that we assume must exist."

Williams (1966) wrote on this point as follows: "How, ultimately, does one ascertain the function of a biological mechanism? In this book I have assumed, as is customary, that functional design in something that can be intuitively comprehended by an investigator and convincingly communicated to others. Although this may often be true, I suspect that progress in teleonomy (the study of the functional organization of living systems, or of evolved adaptations) will soon demand a standardization of criteria for demonstrating adaptation, and a formal terminology for its description."

Investigators who claim that formal studies of design must figure prominently in every study of adaptiveness from the start rarely either develop or exemplify cases of adaptive design. Two exceptions are Cosmides (1989) and Barkow (1984), the latter giving two brief suggestions from the work of adaptively oriented investigators. Symons (1988), on the other hand, in a strong criticism of those who have sought to demonstrate the reproductive significance of human actions while advocating searches for underlying design, fails to elucidate a single design mechanism, or even to expose precisely what he means by the concept. Following Hailman (1977), Borgerhoff Mulder (1987), and Betzig (1989), I suggest that the reason for this failure is that adaptive design cannot be studied except as part of (or following) a 
study of a possible or demonstrated adaptive phenotypic outcome (by "demonstrated" adaptive outcome I mean a direct demonstration of reproductive significance, by "possible" I mean to refer to cases in which adaptiveness must be inferred, but in which there are reasons for doing so, as in the case of cricket communication discussed below). Examination of Symons' (1989) examples ( $p .141$ ) reveals that a considerable knowledge of behavior and its probable and possible adaptive significance has preceded every one of his arguments for attention to mechanisms rather than behavior.

Underlying adaptive design cannot be studied directly. One studies behavioral and other outcomes, judges their reproductive significance-either by direct measurement or by inference (including inferences about the relationship of the current environment to those of the past: Alexander, 1979) — and then infers the underlying physiological and morphological design. Information about psychological and physiological mechanisms can be gained only by observing ultimate expressions of the phenotype-the variations in performance that natural selection actually modifies (meaning those that actually affect reproduction)-in different circumstances. There is no other way. Underlying mechanisms of behavior are modified by selection only because of, and according to, their effects on behavior.

If correct, the argument that behavior must be studied first means that the particular criticisms of such authors as Barkow (1984), Kitcher (1987a, b), and Symons $(1987,1989)$ that, for example, the initial approaches to analyses of female-biased infanticide in stratified human societies (Dickemann, 1979) and the avunculate, which examined their possible reproductive significance (Alexander, 1974, 1979; Kurland, 1979; Flinn, 1981) are wrong, are themselves wrong. ${ }^{4}$

Sometimes it appears that some authors have simply failed to recognize efforts to analyze mechanisms, or perhaps that mere consideration of the reproductive significance of acts leads somehow automatically to the belief that underlying mechanisms are being neglected. This is not necessarily true, and it is unfortunate that the effort to draw attention to the important study of mechanisms is being promoted by the needless disparagement of efforts that are really complementary and essential to it. Such efforts often actually represent necessary and reasonable first steps in showing that evolutionary approaches to human cultural behavior are not necessarily impotent. This

\footnotetext{
${ }^{4}$ Kitcher (1987b) remarks (p. 91): "The main criticism that I level against Alexandrian sociobiology is that it introduces evolutionary considerations in the wrong way by focusing on behavior and not on the underlying mechanisms . . " This statement is not only wrong on the basis that evolutionary considerations must be introduccd by focusing first on bchavior, but also because mechanisms are discussed for virtually every social behavior considered in any detail in Darwinism and Human Affairs, which Kitcher uses for his entire criticism of "Alexandrian sociobiology" and to which the statement quoted above refers. (Thus, the book contains four chapters, with the second concerned almost entirely with the problem of proximate mechanisms; pp. 86-131 represent a single section concerned wholly with development and learning in adaptive behavior and include an extended discussion of the probable, possible, and unlikely mechanisms of kin recognition. For the avunculate, the discussion Kitcher seems to criticize most extensively, there is consideration of possible or probable mechanisms throughout its treatment, see, in particular, p. 174.)
} 
was, for example, the stated intent of my initial exploration of the avunculate and the asymmetrical treatment of cross- and parallel-cousins (Alexander, $1974,1979,1987 \mathrm{c}$ ). Without such introductory studies, focusing on behavior and its adaptive possibilities, those who wish to examine the proximate mechanisms of behavior would have no program to pursue, and this will continue to be the case for every step in the analysis of adaptive mechanisms. ${ }^{5}$

A parallel can be drawn with Darwin's (1859) discussion of sterile castes in social insects. He recognized that individuals who live their lives evidently designed not to produce offspring (their behavior is directed at collateral relatives and not at producing or assisting descendant relatives, and this behavioral fact is the central and driving puzzle identified by Darwin) represented a challenge (he called the divergent phenotypic evolution of castes in these insects "the one special difficulty, which at first appears to me insuperable, and actually fatal to my whole theory"). The task of first importance, which he carried out, was to show that a plausible argument can be made explaining sterile castes by natural selection. He did not prove that his particular "just-so story" was the only one possible, or the correct one: William D. Hamilton developed that part of the argument 105 years later (as hypothesis rather than asserted conclusion, Darwin's argument is better described as a "how-possibly explanation," Dray, 1957; O'Hara, 1988). Nor did Darwin suggest underlying mechanisms or demonstrate the reproductive significance of helping in actual cases. He nevertheles started the process of scicnce in regard to an cvolutionary cxplanation of the "trait" of sterility, and as it turned out his logic actually did represent the correct (and complete) theoretical argument (Alexander, 1979; Alexander et al., 1990).

To criticize those who initially call attention to adaptive possibilities in human behavior for not immediately elucidating the underlying physiological or psychological mechanisms (e.g., Kitcher, 1987a; Symons, 1988) is thus somewhat like criticizing Darwin for not discussing genes in his explanation of sterile castes. All scientific work is incomplete, and within science all

${ }^{5}$ It is crucial not to adopt the attitude that the study of possible mechanisms and the study of possible adaptive outcomes are somehow opposed (Alexander, 1987a; Sherman, 1987; Betzig, 1989). For example, in remarking on a prediction from Alexander (1979) about primogeniture and its possible adaptive significance (p. 158), Kitcher (1987b) writes that "... The psychological explanation I envisage would trace the distribution of parental resources among children to underlying concerns (such as the concern to maximize the welfare of children) and to features of the environment that determine how different courses of action are likely to affect the welfare of the young." Kitcher presents this description of possible mechanisms as a kind of demonstration of how he would have proceeded, as a result of looking for the psychological mechanisms involved, rather than the way I did. Nothing in his sentence, however, conflicts with the brief note from Alexander (1979) on primogeniture, nor adds to it, except that an evolutionary biologist, who would also envision such postulated mechanisms in parents, would see them as designed to serve the interests of the parents' genes through offspring rather that simply maximizing the welfare of children. By his own statement, Kitcher would have been requircd to understand the particular manner of distribution of parental resources, indeed, variations in it, first. The italicized part of his statement suggests that he has the same objections to interpretations of the reproductive significance of human behavior as Symons (1988), discussed later, in connection with polyandry, and by Alexander $(1987 \mathrm{a}, \mathrm{c})$ in connection with female-biased infanticide in stratified societies. 
hypothesis-testing leads only to additional hypotheses to be tested; whether it leads to ideological implications or social practice when it deals with humans is another question entirely. The point is not to disparage those who have gone beforc and been imperfect or incomplete, but to identify what is wrong, if anything, replace it, and proceed with the analysis of mechanisms if that is what seems interesting and important, or with the description of additional adaptive possibilities in behavioral analysis if that is what seems interesting and important.

I bclicve it is uscful to point out these things because abundant reasons, compelling to many, seem always available for accepting uncritically arguments that evolutionary approaches to human behavior can be ignored, and it is all too easy to use needless and unnecessarily confusing attacks on others to promote one's own approach. Progress in science does not require, or call for, cfforts to use particular insufficiencies in method or interpretation of results to disparage, by some kind of pernicious extension, all efforts of the involved individuals, using phrases like "every rung of the sociobiological ladder is rotten" or labeling efforts such as "pop sociobiology" or "Darwinian anthropology" and then attempting to develop the impression that anyone so labeled for whatever reason does nothing useful.

The question of design for (ultimately) reproduction is almost always difficult, and there are multiple ways to infer it. About a half century ago a prominent entomologist scoffed at the likelihood that the sound-making devices on cricket wings had anything to do with communication, and referred to them as analogous to the incidental creaking of the armor of knights of old. Biologists paid little attention to his argument, realizing that devices so elaborate have virtually no likelihood of having appeared incidentally or accidentally. In a similar way, one may infer that any human attribute that gives evidence of being highly evolved, or is too elaborate to be accidental, is likely to have had reproductive significance-to be adaptive in some context. The problem lies not in deciding whether or not complex evolved phenomena are adaptive but in identifying the context. The stridulatory structures on the forewings of most crickets seem easy, because there are no obvious possibilities other than communication-even if communication was poorly, and in large part wrongly, understood at the time of the argument mentioned above (Otte, 1974). Williams (1966) used some examples that are almost as easy to understand: for example, he noted that if a fox, returning in deep snow after raiding a chickenhouse, uses his own tracks, we do not infer that fox feet were evolved to create paths in snow. Similarly, even if earthworms do nice things for garden soil, we do not infer that their digestive systems evolved to help us grow our crops. But we do infer that both fox feet and earthworm digestive tracts did indeed evolve, because they somehow advanced the reproduction of foxes and earthworms, respectively.

I believe that the greatest barrier to general understanding of the potential contributions of biology to human self-understanding stem from naive views of ontogeny and phenotypic plasticity, of the relationships between 
genes and ultimate phenotypic outcomes such as behavior. Such naivete is not restricted to those who have thought only briefly on such questions, or to nonbiologists: prominent evolutionary biologists often display it in its most unsupportable form. I have discussed such a case in connection with femalebiased infanticide in stratified societies (Alexander, 1987c). Symons (1988) provides a parallel example, involving polyandry in human societies, which seems to me so important that it merits detailed discussion here. I quote Symons (p. 138):

In DA [Darwinian Anthropology], however, the tendency to use reproductive data to bypass rather than to illuminate the question of phenotypic design has led some scientists to describe as adaptations human activities that cannot possibly represent Darwinian adaptations. For example, consider Crook and Crook's (1987) paper "Tibetan Polyandry: Problems of Adaptation and Fitness." These authors write that "The central predictions made in a Darwinian perspective is that humans are endeavouring consciously or unconsciously to optimise their reproductive success. It is then a matter of research to discover whether individuals marrying in contrasting ways in different contexts are in fact showing behaviour that does promote their genetic fitness." Their analysis of reproductive data on Tibetans who did and did not marry polyandrously leads Crook and Crook to conclude that polyandry is an adaptation to certain highly unusual environmental circumstances that some Tibetans have encountered in recent times.

Crook and Crook's analysis differs from hehavioral ecologists' superficially similar analyses of nonhuman animal polyandry for the following reason. An evolutionary behavioral ecologist who described facultative polyandry in a nonhuman animal species as an adaptation implies that heritable variation in mating tendencies existed in ancestral populations of the species; that individuals in ancestral populations who mated polyandrously in specific circumstances out-reproduced, on the average, those who did not; that the species possesses at least one physiological or psychological polyandrypromoting mechanism that owes its form to the above-average reproductive success of the facultatively polyandrous ancestors; in short, that the species possesses genes for polyandry. Crook and Crook's description of the specific environmental features to which Tibetan polyandry is supposed to be adapted clearly indicates that they are implying none of these things (also see Dawkins, 1982; p. 17-18).

As I see it, Symons' view of the relationship between genes and behavior omits most of what is important in understanding the adaptiveness of human behavior. To sustain his argument, one must believe either that the ability to learn is not an adaptation or that learning ability did not evolve because it could be (was being) applied to multiple or generalized life situations. I suggest, instead, that all of the implications Symons attributes to an evolutionary behavioral ecologist describing facultative polyandry in a nonhuman animal are likely correct for humans except the last one: that the species possesses "'genes for polyandry, " if one a) removes from the first implication the adjective "heritable" and substitutes "heritable variations in the ability to identify and mimic success (and to identify and avoid failure), or to make suitable cost-benefit decisions about different mating systems under different 
environmental conditions," and b) changes the third implication to read "owes its form in part . . ." The effect of selection on this kind of heritable variation will be to produce an organism ever better at making the costbenefit decisions that will cause it to strive for polyandry under the conditions that will cause polyandry to yield for it increased reproductive success compared to other mating systems. This effect will not yield "genes for polyandry." It will, however, yield genes that increase the likelihood of polyandry under certain conditions. The adaptation is not genes for polyandry, or even polyandry itself, but genes for cost-benefit decisions more effective in maximizing reproduction, in this case by engaging in polyandry when polyandry is reproductively profitable. The same argument applies to Symons' earlier assertion that "cross cousin marriage per se is not a Darwinian adaptation." To my knowledge, no one has argued that it is; but the tendency to carry out cost-benefit decisions that lead to cross-cousin marriages under particular circumstances is indeed potentially a Darwinian adaptation, and there may be no other way to explain why people engage in cross-cousin marriages in the particular situations in which they do. All of the individuals whose work Symons derogates as "Darwinian anthropology" are associated closely enough with me that I can state unequivocally that they have always operated under the supposition that natural selection produces conditional strategies, or behavioral flexibilities that enable (cause) individual humans to adopt particular behavioral alternatives when those alternatives are reproductively the most appropriate (as I have emphasized elsewhere, this statement necessarily specifies, as do all studies of adaptiveness, "in the environments of history"). To deny that this particular form of flexibility represents evolutionary adaptation would leave us wondering how behaviors appropriate to reproduction in this fashion do come about and erase any possibility of explaining the human species as a result of the evolutionary process. Symons' citation of Dawkins (1982) as if it confirms his analysis is misleading, for Dawkins provides the kind of alternative suggested here: ". . . or natural selection had to have favoured the universal occurrence of genes programming some complex "conditional strategy", (p. 28: also see Appendix).

A simpler example may be helpful. During my childhood, my father, a farmer, adopted several practices that no one else in our community had ever used: contour planting, hill dropping of corn, grass waterways, planting of black locust trees for fencepost material on hilly, otherwise useless ground. These practices were viewed with great interest by our neighbors, an activity that $I$ had already become aware was one of my father's principal ways of deciding what to do next in his farming practices. When I encountered the concept of culture in academia I realized immediately that a great deal of it is a matter of plagiarism. Apparently, my father was only different from his neighbors in that he paid more attention to what was being described in agricultural magazines and university circulars, and what was being done by farmers far distant from (as opposed to within) his own community. He 
took those various innovations, churned them over in his mind, decided which ones were likely to work in his particular case, and chose among them on that basis. His neighbors were doing precisely the same things, using slightly different sources of information. Now no one would ever suppose that genes exist in human beings as a consequence of the history of natural selection that specifically contribute to whether or not grass waterways or contour farming will facilitate one's reproductive success. There are no "genes for" grass waterways or contour farming. Nevertheless, I, and all of my associates in the use of evolutionary biology to understand human behavior, believe that it is appropriate to predict that the reasons for the particular manner in which my father used grass waterways involved the likelihood that his behavior would contribute, in the end, to his reproductive success. In other words, we study human behavior as if we expected that innovations of this sort, given a special kind of risk when they are truly innovations, are likely to increase on average the genetic reproduction of those who undertake them (here, the risk is exemplified by the fact, for example, that it was unknown that scourges of locust-boring beetles would, a decade or so later, make the fourth practice listed above an acknowledged failure). We obviously think that this is a legitimate prediction, and that kind of thinking is the basis on which we examine such things as adopting particular cultural practices as being related to the adaptive history of human beings.

What Symons has done, ironically, is to misconstrue the appropriate underlying design, while insisting, even more ironically, that the authors he was criticizing were themselves using reproductive data to "bypass rather than illuminate" the mechanisms he himself could not envision, although he also purports to be the first to seek such mechanisms in an appropriate fashion. Using Dawkins' (1982) terms, in the model described above, alleles would indeed have been replaced by other alleles, across generations. The difference between the arguments of Symons and those of others such as, presumably, Crook and Crook, and certainly myself, is merely in what kinds of alleles have been involved in these replacements, in terms of the particular kinds of effects they have had on the phenotype; the alleles I and at least those "Darwinian anthropologists" in my vicinity have envisioned in this context have never been other than alleles improving abilities to make reproductively appropriate decisions. What I see as the insufficiency in the view adopted by Symons affects every effort to apply Darwinian theory to the understanding of human behavior and its underlying adaptive design. It necessarily leads its proponents into an almost complete blind alley in any effort to explain the human behavioral repertoire. Small wonder at the insistence on emphasizing something else, in the form of underlying mechanisms. It is worth repeating that Symons (1988) describes not a single physiological or psychological mechanism underlying any adaptive performance by humans, and his insistence that it is not necessary to identify neurophysiological structures to study such mechanisms in humans (as opposed, he 
says, to grasshoppers!) causes even the identity of such mechanisms to become mysterious. The question is particularly apt in view of Symons' conclusion (p. 143) that "design is usually manifested at the psychological rather than the behavioral level." This assertion, I believe, is precisely backward: adaptive design is always manifested at the behavioral (or other ultimate phenotypic) level, even if verification or explanation requires (or benefits from) exploration of other epigenetic features, such as underlying psychological, physiological, morphological, and developmental phenomena. If adaptive design is manifested at something called the "psychological" level, then we may legitimately expect that in his rather severe and far-reaching criticism Symons might have brought forth at least one example from the existing body of knowledge about human behavior and psychology. Moreover, we would also expect that the principal students, or recognizers, of evolutionary adaptation would be physiologists rather than behaviorists; this is notoriously not the case.

It is possible to imagine several different ways that genes might give rise to particular expressions of the phenotype (also see Johnston, 1982b, and below). First, genes might cause some phenotypes to produce only a single outcome no matter what ("normal") range of environments the individual encounters. This might happen at a particular age or stage of development. Thus, all humans have hearts, even if their hearts vary (that somewhere along the way hearts became essential to life is necessarily secondary to the fact that normally developing individuals always have them). Second, genes might cause organisms to produce one or another of two or more different phenotypes, depending on some aspect of the environment. Thus, plant or animals raised under long days develop one phenotype (e.g., respectively, flowering; long-winged, flying) and the same forms raised under short days develop another (e.g., respectively, vegetative; short-winged, non-flying). In each case the phenotype is appropriate to the season represented by day length for that species. Third, and most important for understanding human behavior, genes may create phenotypes capable of changing their behavior progressively, or along a more or less continuous axis of variation, as a result of such things as repetition, practice, observation of others, playing out mental scenarios that yield probable outcomes, or accepting the outcomes of mental scenarios of others, transmitted by language.

Flinn and Alexander (1982) postulate two simple and general mechanisms by which adaptation in cultural matters might proceed: abilities to imitate success and to anti-imitate failure. Both abilities quite obviously exist and are employed more or less continually by humans; they exemplify the "nongenetic" aspect of what Boyd and Richerson (1982; 1985) have referred to as the "dual inheritance" system of culture. We learn from both the successes and the errors of others, and from building scenarios within our minds by which we can predict outcomes without actually experiencing them. Indeed, because of language, we are also able-uniquely among all organisms, perhaps-to learn extensively by making judgments about the 
intellectual scenarios of others. As a result, humans have come to engage very extensively in what I have elsewhere called surrogate scenario-building (Alexander, 1987a, b; 1989): that is, primarily through language, we parasitize the mental scenarios of others or hire them to build scenarios for us.

Humans imitate success and anti-imitate failure in efforts to seek power through wealth and rank assiduously enough to leave the strong implication that the tendencies are evolved, hence reproductive. Sex bias in infanticide in stratified societies, for example (Dickemann, 1979), is so closely tied to wealth, power, and rank that to me it seems almost ridiculous to doubt that, as imitation of success and anti-imitation of failure, it is connected to a history of adaptive behavior. No one can doubt that unravelling the hierarchy of mechanisms right back from these psychological ones into physiological and morphological ones, and finding out how things have changed across the centuries, will be interesting and important. But nothing in this suggestion disparages the hypotheses developed by evolutionary biologists examining the reproductive significance of human behavior, that is, through study of the behavior itself as adaptive (Alexander, 1987c). The very nature of the mechanisms just postulated obviates the necessity of thinking in terms of "genes for" behaviors such as female-biased infanticide among elites in stratified societies: the mechanisms utilized are much broader and more flexible, and their operation (and evolution) easier to comprehend.

The above two mechanisms imply that humans have evolved special abilities to judge success and failure, and they cause us to ask in what terms these two outcomes are judged. The apparent answer is, in terms of their effects on wealth, power, and rank. It would appear that, in general, positive effects on wealth, power, and rank have, throughout most of human history, had positive effects on reproduction by providing, ultimately, greater access to superior mates and other resources of reproduction (Alexander, 1987c; Betzig, 1988; Turke, 1989). ${ }^{6}$

A major benefit of the arguments of the various authors cited above is that they focus our attention on three important questions.

What are the actual sources of the perhaps rather widespread uneasiness about efforts to examine the reproductive significance of human behavior? On this first question $I$ argue three separate points. First, the inexactness and inefficiency that Symons (and others) would like to pinpoint typically stem, not from naive attribution of genes for particular behaviors or failure to focus on underlying design mechanisms, but rather from failures to identify and test all alternative hypotheses (in other words, from sometimes omitting or misunderstanding what may be the most likely hypotheses; for examples see Alexander, 1987c). Second, I think there is a failure to understand what

\footnotetext{
${ }^{6}$ One might say that if we are not programmed directly, or in any general fashion, to maximize inclusive fitness (that is, only via hierarchies of domain-specific mechanisms), one of those "narrow" mechanisms may nevertheless be that we are programmed to "win" socially, and to use the same general judgments, with respect to winning, in a variety of social situations.
} 
is being tested and what procedure is being followed. Symons, for example, lists several Darwinian predictions about human societies by different investigators and then argues that, if the predictions had not been met, no general propositions about natural selection would thereby have been falsified or even called into question. Of course not. As Williams (1987) has pointed out, if one's pickup truck does not start he does not assume that the laws of physics are flawed. To find that a strong Darwinian prediction is not met does, however, provide a case that immediately assumes importance, even if its importance ultimately lies solely in uncovering the special and perhaps hidden or non-intuitive reasons for the failure of prediction. Such cases are the stuff of modern evolutionary biology, whether the subjects are human or otherwise. They provide the keys by which the extraordinarily complex and diverse results of natural selection, in humans as well as nonhumans, are ferreted out and comprehended. Morcover, if failures to meet Darwinian predictions continued to accumulate, and were inexplainable in Darwinian terms through closer examination, then general propositions about natural selection would indeed be called into question. The third aspect of this first point is that humans clearly are not aware that their everyday activities might be directed toward reproduction (leaving aside for the moment the question of out-of-context responses to novelty). When confronted with the possibility they typically regard it as ludicrous or with hostility. It appears that these mechanisms work through causing humans to strive for more proximate outcomes that themselves lead reliably to increases in reproductive success, compared to alternative actions. Examples are efforts to attain wealth, power, and status. It is even true that humans often deny interest in these goals, evidently in part (at least) because of conscious and unconscious understanding of the social value of such denials. Unraveling the adaptive psychological or physiological mechanisms that motivate human behavior is not something removed from these revelations but an inextricable aspect of them. The truly intriguing question about underlying design mechanisms such as those involved in cost-benefit decisions about variously novel activities is how these mechanisms typically appear to lead to behavior that enhances reproductive success. It is difficult to imagine that humans could evolve if this had not been true throughout our history. The kinds of studies conducted by Betzig (1988), and Turke and Betzig (1985), and disparaged by Symons (1988), are necessary to see if everyday costbenefit decisions do indeed lead to improved reproduction.

The nature and effects of novelty in the environnents of human behavior is the second important problem exposed in Symons' $(1987,1988)$ critique. Symons argues that behavior (of humans in particular) does not yield evidence of its design for adaptive outcomes, and apparently believes that this is so because humans (confusingly more than other organisms?) now operate in cnvironments different from those in which they evolved. Leaving aside the fact that any such condition will equally obscure evidence of design in 
underlying mechanisms of behavior, intriguing questions are raised about the historical succession of environments of adaptation with respect to human behavioral expressions, in particular the relationship between the prevalence (and recurrence) of novelty in social interactions and its effect on the design of underlying (psychological, physiological, developmental) mechanisms of behavior (see below).

The problem of identifying and specifying the nature of novelty in human environments is the third general question, which Cosmides and Tooby (1987, 1988) explicitly seek to answer. The extent to which the kinds of learning and cost-benefit mechanisms postulated above and elsewhere are specific to particular contexts, that is, whether or not they can in some fashion represent generalizations. $^{7}$

\section{ADAPTIVENESS AND LEARNING THEORY}

Cosmides and Tooby $(1987,1988)$ believe that the classical view of learning, as a "domain-general" mechanism, or simply as behavior influenced by the environment, is too unfocused to be useful in exploring the specific backgrounds of adaptive behavior. They argue convincingly that what must underlie adaptive phenotypic outcomes, at least eventually, are mechanisms that are specific with respect to the "environmental domains" in relation to which they function. This argument, however important, is not new: Rozin (1976), for example, made it, starting with the more widely used phrase "general process view" (of learning: Seligman, 1970) (also see Lumsden and Wilson, 1981; Johnston, 1982a, b; J. L. Gould, 1986). I think that virtually every evolutionary biologist or evolution-minded social scientist already adheres to some such position, and, moreover, would also expect the existence of a hierarchy of such mechanisms becoming increasingly specific with respect to environmental domains or targets, and how those domains or targets are deal with, as one works "backward"' in development and experience toward the zygote itself, or the primary products of gene action. Rozin (1976) explicitly postulated such hierarchies among organisms in general. Such

\footnotetext{
${ }^{7}$ I believe that the developmental and functional dichotomies that typify nearly all discussions of human activities, not only in biology but in the human-oriented sciences, philosophy, and the humanities, are inadequate, and responsible for much unnecessary misunderstanding and acrimony. Thus, culture is not analogous to icing on a cake, a behavioral veneer on a phenotype that is seen as somehow prior to cultural effects. There is no "biogram" that is analogous to a cake prior to icing, or to some amorphous half-developed phenotype ready for the cultural veneer. In development of the organism there is only one dichotomy worth sustaining: genes and environment (internal as well as external). When initial gene products are produced the environment has already begun its influence, and culture may even have already yielded effects. Moreover, humans are not unique in that multiple avenues of development (or learning) are possible depending on environment; rather, in this they are like essentially all forms of life (excepting, perhaps, some viruses that live parasitically). Cultural variations are special because of their complexity and diversity, and because of the particular way they can change cumulatively through learning, but in no other respects (also see Appendix).
} 
mechanisms, moreover, have been hypothesized in studies of song and other learning in birds (Konishi and Nottebohm, 1969), kin recognition in many kinds of animals (e.g., Holmes and Sherman, 1983; Waldman et al., 1988; and below), and virtually every case in which biologists are attempting to understand the physiological and developmental backgrounds of behavior in nonhuman organisms (Johnston, 1982a, b; J. L. Gould, 1982, 1986).

One of the interesting sets of problems in considering such hierarchies (again, working backward in ontogeny) involves the distinction between learning and mechanisms so specific and so limited with respect to the outcomes they specify that we no longer refer to their operation as "learning." What criteria are to be used to make this distinction, and to determine whether or not there are multiple levels in the hierarchy on one or both sides of the distinction between "learned" and "not learned" mechanisms or outcomes (see below)? Lumsden and Wilson (1981) divided "epigenetic rules" into "two classes that occur sequentially within the nervous system": 1) the "more automatic processes that lead from sensory filtering to perception" (i.e., constraints or guides attributable to known morphological or physiological phenomena), which they termed "primary" and 2) "the evaluation of perception through the processes of memory, emotional response, and decision making through which individuals are predisposed to use certain culturgens in preference to others," which they termed "secondary." These authors, not cited by Cosmides and Tooby, undertake the most wide-ranging and ambitious review and discussion of human behavioral epigenesis in biological terms to date. Their focus seems to be more on the nature of genetic underpinnings of behavior, and other phenotypic differences derive from genetic differences, rather than on the question of the adaptive significance of particular phenotypic outcomes (including both behavior and developmental and physiological mechanisms). In other words, Lumsden and Wilson were concerned with demonstrating the existence of genetic and developmental phenomena whose complexity would indicate adaptiveness in some context.

Cosmides and Tooby (1987) also argue that the "domain-general" or "general-process" view of learning has resulted in the misapprehension that anything other than a tabula rasa is evidence of a "constraint" on learning (Seligman and Hager, 1972; Hinde and Stevenson-Hinde, 1973, pp. 301-2), "The tendency to refer to . . . innate knowledge as 'constraints on learning' is perhaps the result of the mistaken notion that a tabula rasa is possible, that learning is possible in the absence of a great deal of domain specific innate knowledge ... that the human mind was 'built down' from a more general-purpose cognitive system present in our ancestors. Yet such a phylogenetic history seems far from likely; it presumes that our primate ancestors had a capacity to learn that was broader and more powerful than our own."

This general premise, which I accept (with reservations about the use of "innate," e.g., see below and Alexander, 1979, pp. 279-280; 1987a, pp. 
10-11), was also argued extensively by Rozin (1976), Johnston (1982a, b), and J. L. Gould (1986) (also see Tierney, 1986). Nevertheless, constraints on a particular conception of learning, or on a process of generalizing learning as an adaptive mechanism, can be imposed continually as learning evolves, without the actual situation ever approaching the conception. Moreover, as Rozin (1976) suggested, developmental and evolutionary changes in learning sometimes may be appropriately seen as evolved constraints (see also Johnston, 1982a, b; J. L. Gould, 1986). For example, some songbird species "memorize" songs heard more or less throughout their lives; others do so a) only as juveniles in the nest before starting to sing themselves, b) then and also when starting to sing themselves, or c) primarily when starting to sing themselves (summarized by Slater, 1989). Some species learn their own species' songs preferentially although subjected to the songs of other species, others develop repertoires including songs evidently learned from dozens of other species (e.g., Dowsett-Lemaire, 1979). Some species learn preferentially from individuals with which they associate, even if that is a member of another species; others do not (Baptista and Petrinovich, 1984; Kroodsma and Pickert, 1984; also see Slate, 1989; Alcock, 1989). Similarly, "imprinting" of the attributes of offspring (or parents) may occur only within a few minutes of hatching or birth. Such timing and context restrictions (constraints), often unusual enough to be set apart (e.g., as imprinting) from other kinds of learning by biologists, may virtually eliminate errors in natural situations; many forms also occur in humans. Such cases seem unlikely to represent incidental effects of pleiotropy or senescence and may often indicate evolved constraints on learning (cf. Rozin, 1976). Parallel examples could be gleaned from learning that carries special kinds of restrictions with respect to what patterns of information are allowed to influence subsequent behavior. Of course, evolution of constraints per se is especially likely to be a correct interpretation if narrow timing of learning, or other kinds of restrictions, are limited to a few species in a large group, and on other grounds as well, appear to be a phylogenetically derived condition. All evolutionary changes in learning that narrow its stimulus targets or eliminate errors occurring as a result of a too-general or too-broad focus (or as a result of novel chances for error following environmental change) may legitimately be seen as "constraints" on learning, as a subset of the general evolution of canalization of the phenotype.

The basic message of Cosmides and Tooby (1987), and others who focus on the development of adaptive behavior, is that a general rule such as "maximize inclusive fitness" cannot be a useful guide for conducting life adaptively without a very large number of narrower, more explicit underlying rules that "frame" the individual problems encountered in day-to-day living. This view, which of course implies that kind of explicit guidance of development that a history of selection would yield, is also probably shared by virtually all evolutionarily-oriented scientists. The emphasis and new attention supplied by Cosmides and Tooby, which would have been enhanced by 
utilizing earlier writings taking the same approach, have undoubtedly had a positive and revitalizing effect on the topic. The question I would like to address eventually is: How does this argument and the studies of learning that underlie it, influence the effort to understand how components of the human psyche have evolved (Alexander, 1987a, 1989, in press)?

A good description of the contrast between the two extreme views of learning is given by Gleitman (1984: 553), in relation to language learning:

Many linguistic theories postulate not only a distinct mental representation or faculty of language (a 'language organ,' in Chomsky's wording, functioning as autonomously as, say, the liver), but a highly modularized system internal to language itself ... Proponents of such positions expect that language learning will be largely maturationally determined, that the maturation functions may be quite separate from those in other cognitive domains, and that different modules within the language systems may mature quasi-independently. In clear contrast, most developmental psycholinguists hold that language acquisition is best described by a global learning procedure that is responsible for the acquisition of, e.g., knitting, arithmetic, and ancient history as well as, say, English . . .

It is worth noting that Williams' (1966) arguments for adaptiveness from "design" (by natural selection) do not negate either of these positions. On the other hand, as already noted, the "general purpose" model of learning raises acute questions about adaptiveness from design, with regard to the generality of mechanism and its relationship to environmental novelty.

\section{ADAPTIVENESS, LEARNING, AND NOVELTY}

Symons $(1987,1988)$ implies that human abilities arising from a general purpose effect of learning cannot be viewed appropriately in evolutionary adaptive terms. Thereby, he incidentally raises the question whether there has been design by natural selection of learning systems prepared explicitly to deal with novel situations, even within a predicted range. ${ }^{8}$

To deny that learning has evolved to deal with novelty seems to me to deny the possibility of the most distinctive psychical attributes of humans having evolved. (Robert Smuts, personal communication, has expressed the same thought this way, ". . . understanding how humans respond to novelty is what any true science of human behavior must be about.") The issue is not trivial, as it bears upon the origins and reasons for acceptance and spread of learned social and cultural patterns of activity which are often, even typically, novel. One might imagine that such phenomena indicate that modern human behavior simply cannot be connected to this history of natural selection that produced it, therefore, that there is no need for those who engage

\footnotetext{
${ }^{8}$ Novelty can be thought of as a) unprecedented events within a predicted range, or a range characteristic of the organism's environments of evolution, or b) events outside the range of an organism's evolutionary environment, even if within a predicted range.
} 
in "textual analyses" of documents, language, artifacts, and other creations of human social life from the humanities and the social sciences to connect their analyses to the human history of natural selection. I propose, instead (also see Alexander, 1987a, b; 1989), that consciousness is a vehicle (mechanism) of a kind of "general purpose" learning, evolved explicitly (designed by natural selection) to prepare us for a flow of novel social circumstances, at least in the sense of tuning us and motivating us with respect to a myriad of cues and predictive contingencies in the actions of others and in the details of the contexts of those actions (which actions may often be novel in the above senses). I would also argue that, if, as many seem now to believe, the human psyche is evolved to deal with intraspecific social situations, as opposed to problems involving tools, predators, food-getting, and the physical environment (Bigelow, 1969; Humphrey, 1976-1987; Alexander, 1987a, b, 1989, in press; Rose, 1980, 1983; Wynn, 1988), the environment of its operation has not changed so profoundly in the last several thousand years as many investigators seem to think. ${ }^{9}$

Contrary to depictions of prehistoric hominids as resembling dull, moronic, and socially inept modern humans, and sometimes as being physically weak, vulnerable, and "half-evolved" as well, I suspect that our ancestors at every stage possessed greater agility and perhaps even more physical strength than modern humans, responsiveness to expressions and movements and quickness of visual notice to subtle evidences of changes of mood and intention in others that would be astonishing to us, and distinctive and complex social capabilities of a sort that would cause us to view them as different from ourselves rather than simply inferior or "not quite human." I also expect that much of recent human psychical evolution has consisted of the elaboration of systems for complicating and concealing such changes of mood and intent, primarily by introducing deceptions of various sorts, and, in turn, for counteracting the continuing pattern of ever more subtle and sophisticated manipulations.

Adaptiveness in the mechanisms of human bchavior may be regarded by some as paralleling that involved in the structure and function of hands. Hands are useful in almost innumerable circumstances, some for which they

\footnotetext{
${ }^{9}$ Humphrey (1976) first explicitly and extensively developed the idea that the human psyche had evolved in a social context. He did not, however, give a reason why humans should have continued to live socially under conditions that would lead to strong selection for the brain and the psyche; nor did he appear to understand the necessity for such a reason. The arguments of Darwin (1859, 1871), Keith (1949), and others, expanded and developed primarily by Bigelow (1969), Alexander and Tinkle (1968), Carneiro (1970), and Alexander (1971, 1974, 1979, 1987a, b, 1989. in press), suggesting that humans have long lived in competitive and aggressive social groups as part of a within-species balance-of-power race, not only provide the context that Humphrey omitted but, as perhaps all of these authors understood, require the outcome that Humphrey independently postulated, that the selective forces molding the human brain and psyche are primarily social. Hamilton (1987) suggested that "In general it is the accuracy of forecasts in increasingly untried situations increasingly distant in time, that is the measure of the possession of intelligence." He did not cite or discuss the arguments of previous authors, however, nor did he distinguish social and other (nonhuman) forces such as predator and prey strategies and navigational problems.
} 
were designed and some not (i.e., some of their uses have in the past resulted in the saving of changes leading to their present-makeup and others have not). Some present uses of hands were designed for them, such as typewriters, telephones, and "hand" tools. The question about learning or consciousness that parallels the design of hands is whether or not hands were designed to deal with novel situations (e.g., any situation within some range of contexts). My view is that they were not, but that they are now so used because some aspects of learning and consciousness have been so designed.

We identify adaptiveness as an outcome of the effect of repeated events upon the genetic materials. Repeated events are by definition not novel. Even though the circumstances encountered by each individual organism during its lifetime may be novel, as a set, nevertheless, the organism's developmental and other responses are seen as adaptive only if (the assumption is because) their appearance hinges on aspects of the individually unique environment of the individual organism having been present repeatedly in the environments of the organism's ancestors. The question generated here is: Can an organism be prepared by natural selection explicitly (i.e., not merely incidentally) to deal with novel social circumstances? We already know that such preparation has occurred in other contexts, for example, the immune system, in which antigens never before encountered by the organism or its ancestors may be controlled by the production of antibodies more or less specifically binding the antigens, the presence of which stimulates their production (Edelman, 1973, 1987). Edelman (1987) argues that the nervous system develops, in general, in a way commensurate with the notion of being prepared to deal with novelty; "One of the fundamental tasks of the nervous system is to carry on adaptive perceptual categorization of an 'unlabeled' world-one in which the macroscopic order and arrangement of objects and events (and even their definition or discrimination) cannot be prefigured for an organism ..." (p. 7) and "... selection upon degenerate repertoires of reentrantly connected neuronal groups ... can result in effective categorization without a preexisting explicit program describing the objects to be categorized" (p. 8). Both the immune system, and the nervous system, as Edelman sees it, are also ". . . consistent with the selectionist notion that there is no general-purpose animal-only the adaptive evolution of particular sensory sheets and adaptive motor ensembles and of the somatic principle itself evinced by particular mechanisms within the phenotype." (p. 19). This view is consistent with the notion of learning mechanism as special-purpose phenomena without precluding the notion that social learning can take the form of a special (or general) purpose mechanism evolved to deal with social novelty.

Consider the ability of humans to construct scenarios and visualize their outcomes, and to use this activity to respond appropriately to novel combinations of social circumstances. We can easily imagine that the background of such ability is that those possessing increasingly elaborate and effective forms of it throughout human history outcompeted their fellows in the scram- 
ble for the resources of reproduction. It is difficult to understand scenariobuilding except as based on individual experience, whether direct or only as a result of tuning in on the scenarios of others. In this sense it is not an activity based on novelties, and this is a sense perhaps comparable to the sense in which the unique environment of each developing organism is nevertheless not unique in historical terms. An organism's lifetime environment, after all, has the possibilityof being unique in the sense that it is a unique combination of events, none of which is individually unique in the phylogenetic history of the organism. The social lives of individual humans undoubtedly include innumerable unique events, and in some ways the extent and nature of this uniqueness is reinforcing so that it magnifies across generations, for example, as a result of cultural change. Unique social events can be crucial to the success of individual humans. Are humans only incidentally prepared to cope with such novelty, or were they somehow selected explicitly to deal with at least some aspects of it? ${ }^{10}$

Suppose that the most significant barriers to reproduction, repeatedly, over long periods, are limitations on the organism's ability to deal with events that have never been encountered during phylogenetic history. Such a scenario can scarcely be long applicable without the introduction of novelty at an ever-increasing rate. In some sense this kind of change has characterized the social and cultural life of evolving humans (which Lumsden and Wilson, 1981, aptly termed the only "eucultural" species). Abilities to utilize unique situations in the ontogeny of scenario-building capacities are one way of coping with such novelty. The question now seems to focus on what underlying ability might sharpen such capacities, and one thinks immediately of patterns of logic or any system that might provide assistance in deter-

\footnotetext{
${ }^{10}$ Novelty in social matters can take many forms and be variously profound; modern social situations, moreover, are not necessarily irrelevant. For example, consider my appearance in a courtroom some years ago to defend myself. I had never been in a courtroom before, this yielding sufficient novelty on so many fronts as to cause the judge to warn me that the courtroom is not a place to practice being a lawyer. I had never encountered the prosecutor before, so that not only his personality but the manner of his presentation and the evidence he would use could not be predicted entirely by me. I had met the state highway patrolman who testified only once late on a dark evening along the highway; and I had no knowledge which of the two patrolmen who had ticketed me would be testifying. The judge was new to me. I could not know what kind of argument the patrolman would use. I did not know that the prosecutor had been notified of my letter to the State Department of Justice complaining about the behavior of the patrolmen and was explicitly prepared to counter my arguments. All that served me were a) the resolve that come from my knowledge that I was innocent (and my desire to show my children, who also knew it, that, contrary to their belief, this fact could prevail) and b) the fact that I had spent almost the entire 24 hours preceding the trial constructing sequences of possible scenarios about the exchanges I would have with these people I had never met in this situation I had never before experienced. Nevertheless I won; and decisively, so that the judge stated at the end that he not only ruled me innocent, but declared as well his opinion that $I$ could not have done what I had been accused of doing. To me it was astonishing to realize that I had scenario-ed my way through all but two of the situations that actually occurred in the courtroom beforehand, and that in those two cases I was able to anticipate (and change) the probable outcome by deliberating attempting to do so, while also deliberately slowing the procedure to allow myself time to imagine the next steps. Extensive novelty is typical of social situations, some of it more profound and some less profound. The argument $I$ am making here is that we are cvolved to strive as $I$ did in this casc, to deal with novelty on many fronts in social situations. and to "win" when conflicts of interest arise, as are our adversaries.
} 
mining cause-effect relationships among social events of importance to the individual. The eventual question is whether any such system exists in humans, and failure to identify such systems in some contexts may not deny the possibility of their presence in others. Thus, our inability to deal logically (or adaptively) with such environmental changes as an overabundance of inexpensive sugar, cigarettes, alcohol, or other pleasure-inducing or addictive drugs may not tell us anything at all about the absence of generalized learning systems that function in social life. It is also true that most considerations of the manners in which we deal with these kinds of novelities entirely omit their social significance; cigarettes may represent a net cost in their tendency to cause cancer, but until that issue had become an important part of the way cigarette smoking is viewed by the public the overall effect of cigarette smoking could have been reproductively positive because of status or other social effects from being a smoker.

Novelty in the environment can be dealt with by extracting from memory fragments of relevant information from prior experiences that either parallel or represent parts of possible future episodes, and then combining these fragments so as to review and prepare for alternative novel future possibilities (that is what Hamilton, 1987, called "untried" situations).

Whether or not selection favoring systems enabling us to respond appropriately to phylogenetically novel social situations has occurred, it would seem that some aspects of learning are in fact appropriately labeled as "domain-general" or "general-purpose." Thus, "classical conditioning" is a generalization that can be applied, in all likelihood, to every form of animal life. Moreover, it is useful in a bewilderingly wide array of adaptive (life) situations. In each of these life contexts, of course, conditioning may operate as a highly specialized mechanism designed for a particular behavioral outcome. ${ }^{11}$

I would expect that different generalizations about behavior changes appropriately labeled as "learning" could be arranged in a hierarchy of decreasing degrees of universality, increasing likelihood of independent evolutionary origins (even if similar in form), and decreasing extents of use in different behavioral domains or life contexts. If this is true, it in no way detracts from the fact that any particular instance of learning in any particular species should be expected to be tuned and restricted to some particular adaptive use, and to be, in that sense, "domain-specific." But many aspects of learning as a phenomenon, are, in the sense of being transferable between "programs," also domain-general. It is as if learning is a special case of changes of function during evolution, evolved in such a way as to be easily transferred between "programs," and having a special likelihood of usefulness in multiple life contexts.

\footnotetext{
${ }^{11}$ In other words, the genetic and ontogenetic processes giving rise to the physiological mechanisms underlying classical conditioning may be generalized, iterating some of their actions in the epigenetic production of conditioning mechanisms that operate in widely different life contexts. Of course, "classical conditioning" can be defined or used sufficiently independently of physiology to render this hypothesis inapplicable (see Herrnstein, 1977).
} 
An argument made with increasing frequency among those concerned with the adaptive significance of human behavior is that humans today live in environments quite unlike the early Plesistocene environment in which we supposedly evolved our most distinctively human attributes. It is sometimes argued, from this beginning, that the novelty of our modern environment precludes any study of behavior as adaptive because there are no "natural" contexts available for behavioral performance today. If, however, the human psyche has evolved as a device for dealing with social problems, then to a large extent this argument is impotent. Intraspecific social problems faced by modern humans almost certainly resemble, in general-and surely often in particular as well-those faced by humans ever since humans were passing through the transition from a prehuman state. I am suggesting that we are addicted to soap operas (and all other condensed and elaborate social dramas we call theatre) because our ancestors literally endured similar circumstances in small groups of relatives and friends for thousands of generations, in which nothing was more important than experience and skill in manipulating the people and events involved, and such experience and skill came from observation as well as actual participation in particular events. This proposition surely deserves investigation, in view of the increasing emphasis on social behavior as the prime selective force molding the human brain (e.g., Humphrey, 1976, 1987; Alexander, 1987a, 1989, in press).

For two reasons, then, an evolutionary and adaptive approach to understanding human behavior may have considerably more merit than many would grant: the social environment, which may be the primary force behind the evolution of the human psyche, 1) may not have changed as much as other aspects of the environment and 2) may have for a long time favored abilities to deal with certain kinds of environmental (especially social) novelty.

\section{LEARNING AND ITS ALTERNATIVES}

One way to start answering the questions posed above is to characterize extremes in the range of variation in the nature of the "Darwinian algorithms" that underly adaptive human behavior (also see Lumsden and Wilson, 1981; Johnston, 1982b). This range, I expect, will incidentally encompass the range that occurs in the phenotypic repertoires of all nonhuman organisms as well.

Consider, at one extreme, the following example (from Alexander, 1987a:257; see also, Lumsden and Wilson, 1981, pp. $83 \mathrm{ff}$.);

"Organisms that live in environments containing deadly snakes evolve to acquire avoidance responses to the snakes before they are ever encountered. As individuals they do not rely upon trial and error learning to react to the danger of the snake's strike; if they did they would be dead. Because we usually do not know how such preprogrammed responses appear in in- 
dividuals, or even the context of their development, they. are commonly given the convenient (but [developmentally] uninformative) label of innate.' "When this term is used, it appears typically to be intended to imply that no learning was involved.

Avoidance of snakes by humans is a case in which the "domain-specific" nature of the mechanism penetrates into the observed and "thoughtabout" behavior; it directly involves the actual phenotypic outcome-the adaptive result. Yet the most we can say about the underlying mechanism is that, whatever it may be, it apparently prepares us behaviorally before the event in which the behavior is useful arises. Even if, as Cosmides and Tooby (1987) assert, "innate" is not an alternative to "learned," it is still true that learned, when applied to any particular behavior, is a positive term meaning that we know something about the ontogenetic or experiential background of the behavior. ${ }^{12}$ Innate, on the other hand, is a negative term, essentially stating that we know nothing of the background of a behavior except that it is somehow cryptic and does not seem to involve the obvious changes in response that would have enabled or caused us to regard it as learned. ${ }^{13}$

Fodor (1983) distinguishes "innate" (as an alternative to "some sort of learning process") and "hard-wired" (as "associated with specific, localized, and elaborate structural neural systems" and an alternative to "implemented" by "relatively equipotential neural systems"). Johnston (1982b) suggests two "adaptively equivalent" ways that invariant outcomes might eventuate during ontogeny: 1) by "strict genetic control over development, so that the outcome is insensitive to [variations in] the conditions under which it occurs" (innate) and 2) by ". . . a developmental sensitivity only to environmental factors that are themselves invariant within the animal's developmental niche"' (pre- or hard-wired?) (pp.419-420). One difference between the two, he argues, is that in the second case "Outside the [developmental] niche, this system either produces non-adaptive phenotypic outcomes or fails to develop." Tierney (1986), Alcock (1989), and others emphasize that the distinction between the kinds of behavior indicated by these labels is not always clear.

In attempting to describe the range of possible and probable mechanisms underlying behavior known to be learned, one might begin with the various kinds of learning and its presumed alternatives (see J. L. Gould, 1986): im-

\footnotetext{
12 This observation does not obviate the fact that the biases of some individuals may cause them prematurely to declare behaviors with unknown ontogenies to be "learned"; instead, it emphasizes that there is no way to identify "innate" behaviors that parallel the identification of behaviors as "learned" after conducting experiments which prove it.

13 "'Hard-wired" or "pre-wired," other terms often used for such postulated mechanisms, at least have a positive connotation, since they imply that some contingency other than the one which will yield the adaptive phenotype is responsible for the mechanism (or circuitry). From the point of view of practical interference with, say, behaviors deemed undesirable, as in either human criminal and other aggressive actions, and animal training, "innate" implies "unchangeable" or "irreversible," while "hard-wired" at least implies that if we can discover the relevant contingency we can change the mechanism (wiring).
} 
printing, classical conditioning, operant conditioning (trial and error), alpha conditioning (covert and overt) habituation, sensitization, and "higher order learning" (called "cognitive trial and error" by J. L. Gould, 1986). In discussing constraints, limitations, or restrictions on learning, one could begin with restrictions of the senses to receive only relevant information (excluding, including, magnifying, etc.), sensitive or critical periods, and selective learning, memory, or forgetting abilities. J. L. Gould (1986) uses a dozen or more terms that might be considered to represent models of mechanisms underlying learning: sign stimulus response, feature detectors, selective learning (learning and behavioral biases, spontaneous preferences), cognitive maps, neural "'albums, " temporally defined memory arrays, recognition wiring, cue biases, default routines, etc. Similarly, Rozin (1976) speaks of inaccessible programs, different levels of accessibility, calibrational learning, cognitive unconscious, and unconscious inference. One can add many ordinary concepts such as alteration of pleasure or rewards, or of avoidance of pain or punishment; acquiring abilities to imitate success or anti-imitate failure; acquisition of search images, and many others. All of these labels, which are not necessarily parallel or of equivalent ranks to one another, imply models for processes postulated to underlie particular behavioral expressions, and indicate that there has been considerable effort to elucidate the design of the mechanisms underlying behavior in adaptive contexts.

One could actually continue to discuss the range of variation in "Darwinian algorithms" applicable to human behavior using the same well-known example of responses to snakes. For it is also true that humans tend to respond negatively to the actual strikes of snakes (poisonous or not), that they pay attention to the interactions of others with snakes, that they respond to instruction and admonitions about snakes and their danger (and accounts of the interactions of others with snakes), that they seek out such instruction, and that they are keenly interested in the use of others' scenarios about the danger (or lack of danger) from snakes. Moreover, humans also use the reactions of others to snakes to startle or frighten them, to create humor at their expense, and to show their own fearlessness or skill. In other words, humans use snakes, and human reactions to snakes, to elevate their own status and lower the status of others, and to manipulate others socially. One might say that, with snakes as the environmental medium, they use the consciousness, cognition, emotions, linguistic ability, and personality traits of themselves and others, all of the commonly listed aspects of the human psyche, to compete (both directly, and indirectly, via cooperation) by social manipulation. Using some of Rozin's (1976) terms, the "pre-wired adaptive specialization" that causes us to behave appropriately (to inclusive fitness maximizing) is "accessible" to a variety of the conscious contexts in which we influence our inclusive fitness through social machinations.

What is the nature of the mechanisms or "Darwinian algorithms" that might underlie the above uses of the psyche with respect to snakes? To explore them would relate efforts to explore the proximate mechanisms of 
adaptive behavior in humans to efforts to consider the evolution of the psyche. I have tried to provide insight into the nature of the psyche by playing information about its probable evolutionary background against information about its probable adaptive significance or current function (Alexander, 1989). In this effort I have become especially interested in consciousness and scenario-building. Rozin (1976), Cosmides and Tooby (1987, 1988), Symons (1987, 1989), Johnston (1982a,b), J. L. Gould (1986), Lumsden and Wilson (1981), and others are trying to do approximately the same thing, primarily by focusing on the nature of the underlying proximate mechanisms that lead to human behavioral outcomes in modern environments. The two efforts should be complementary.

One unfortunate fact is obvious from the start: In any such efforts to analyze, we proceed as quickly out of the conscious-which, paradoxically, represents our system for analysis of itself-in one direction as in the other. If it seems abundantly clear to each of us that our behavior is not driven by a conscious realization of the value of inclusive fitness maximizing, and that this goal therefore does not in any motivational or deliberate sense drive our behavior, it is equally clear that we do not carry in our consciousness any comprehensive understanding, or perhaps even any glimpses, of the mechanisms and personal history that underlie our preparation for dealing with snakes, and as well typically none that tells us how we became vulnerable to the manipulations of others in the context of snakes, or (at least sometimes) how to escape those manipulations. Nor can we locate or identify by "ordinary" accessing or consciousness (as opposed to accessing via the procedures of science) the mechanisms that inform us about sexual preferences, incest avoidance, kin recognition, or any number of other things that are centrally involved in our everyday social lives. In fact, the extensiveness and complexity of the "cognitive unconscious" (Kihlstrom, 1987) and the evident superficiality and limited purview of consciousness, cause the evolution of consciousness (considered in light of adaptive consequences of behavior and "Darwinian algorithms") to become an even more intriguing and difficult question.

A misleading aspect of terms such as "hard-wired" and "innate" (as well as "genetically determined" and "instinctive"), when they are used to cover ignorance of developmental backgrounds of human behavior, is that they imply that the involved phenotypic outcome either was not learned in any fashion, or was not learned in the explicit context in which the eventual outcome functions; yet all that we really know in most cases, for humans, is that whatever led to that phenotypic outcome, it is not now conscious, may not have been conscious when it happened, and even may not be accessible to the conscious at any time (indeed, absence of conscious memory is often sufficient in humans to cause a quick leap to the concept of "innate" or "pre-wired"). Even if there is the additional implication that, as with avoidance of inbreeding (or incest), there has to be a second more narrowly determined mechanism underlying the particular learning situation (and 
mechanism) that can actually be demonstrated (that is, avoidance in sexual behavior of individuals associated with particular ways at particular development stages or times), we have known all along that there must be hierarchies of events and mechanisms underlying all phenotypic outcomes, with increasing restrictions on their domains of influence as one moves toward the zygote.

In some sense, the problem is that we have not yet defined learning adequately, even in the most general sense. This is why we use vague terms such as "innate" and "pre-wired" to refer to behaviors that we wish to contrast with learning. It is probably also why concepts such as "boundaries" and "constraints" have arisen in connection with learning studies. In a sense, if we do not know what learning is not, we cannot specify what learning itself is. And, in turn, we cannot know what kinds of life situations can be expected to lead to the evolution of learning, as opposed to ontogenetic or developmental changes that are not appropriately so terms. The reason we have not defined learning properly, in my view, is that despite copious writings on the topic we have generally failed to investigate learning as a mechanism of evolutionary adaptation or reproductive success.

Some years ago I lectured in an introductory honors psychology course on the phases of migratory locusts. I described the differences between the two extreme morphs-the migratory and statary phases-which differ profoundly in morphology, physiology, behavior, egg size, clutch size, etc. (Key, 1950; Kennedy, 1956). I noted that they are so different that they were originally described as different species. I described laboratory experiments showing that tendencies to change toward one or the other extreme had been brought about by visual, chemical, and tactual stimuli. To a biologist, familiar with not only phases but the different castes of the eusocial insects, also brought about by environmental differences such as nutrition and pheromones (Wilson, 1971), migratory and non-migratory phases excite interest but not disbelief. In the question-and-answer period, however, the undergraduate social science majors in this class began to express doubts that what I had just told them was truthful. I was so astonished at this reaction that I paused for a moment to stare at the class. During this brief interval the instructor called out from the back of the room, "It's just another form of learning!' The class visibly subsided, at least now on the way to being convinced of something other than my lack of veracity or entomological expertise. I left the class wondering precisely what message had been conveyed by the instructor's words, and, not less, what he thought had been conveyed.

Biologists probably do not often refer to the manner in which migratory locusts acquire the traits of one morph or another as "learning." Indeed, I suspect that most of them would find this application of the word puzzling or uninformative. Why? Let's take a slightly simpler case, mentioned earlier: day length is a "contingency" of season which indicates infallibly whether the next several weeks or months will be winter or summer-a growing 
season or a diapausing season. Evidently for this reason, photoperiod is widely used by plants and animals to adjust to one of two different patterns of life activities. We do not typically call this kind of response "learned." The reasons may be that the organism is prepared to accept photoperiod differences before they occur, and it has only one response to a given photoperiodic regime: if days are long, or becoming longer, the organism responds in one way; if they are short, or becoming shorter, it responds in another. If the organism responds the wrong way it will die, just as with the initial response to a poisonous snake. It has no chance to correct the error. The mechanism is essentially the same as with locust phases and the "prewired" response to poisonous snakes, where there is also only one alternative for each of two situations, in the latter case with and without a snake, respectively. This mechanism is not the same as those generally employed in social learning situations by humans.

I suggest that the concept of learning applies to mechanisms that have evolved in life situations in which correctable adaptive errors occur, and that learning evolves when abilities by individuals to correct adaptive errors result in a net benefit to them. This definition, and the resulting limitation, stipulates repetition of acts, with change occurring during or as a result of the repetitions. It explicitly excludes situations in which there is no possibility of error, or in which there is no chance to correct errors. Therefore, it excludes 1) situations in which there is only a single satisfactory outcome, whether or not there are preceding contingencies on which to practice for its realization, and 2) situations in which there are multiple possible outcomes but no preceding contingencies on which to practice to achieve the most adaptive outcome, or none that can be used reliably to indicate which contingency will be the most adaptive one in a particular instance. Note that "preceding contingencies" here refers to contingencies within the lifetime of the individual; such contingencies do not exclude evolutionary novelty. Note also that repetitions and practice may, in humans at least, take place entircly in the mind (Alexander, in press).

These restrictions on the concept of learning have immediate consequences for our interpretations of familiar situations. Thus, they raise questions about why any animals (such as geese, ducks, chickens, and some birds) use a learning experience called 'imprinting"' to determine the appropriate species and sex toward which to direct mating behaviors as an adult. This question might have been raised anyway, because thousands (probably millions) of animal species do not involve any such experiences in the development of their sexual "preferences." They acquire the ability and tendency to direct sexual activities toward appropriate partners without evidence of any kind of prior experience with members of their own species. Perhaps students of bird behavior did not raise this question because birds learn so many of their social and other responses in fairly obvious ways. Thus, ornithologists are acutely aware of the problem of how cowbirds and other parasitic birds sing appropriate songs or identify appropriate mates 
(West and King, 1985), while entomologists rarely think about the question for insects, even though most insects have even less opportunity to learn about appropriate mates.

It seems insufficient to suggest that birds rely upon an appropriate learning experience early in life to develop appropriately directed sexual behavior solely because the iearning experience is highly likely to be correct. Unlike the situation of an organism that uses day length to determine the appropriate life strategy, there not only is a chance for error (that presumably would not be present if the behavior were developed without the necessity of social experience), but there is no chance that two or more potentially successful alternatives exist that must be differentiated; the class of suitable mates includes only members of the other sex in the same species. We are led to the hypothesis that this learning experience has some other significance in which such alternatives do exist, and in which the particular social experience that results in appropriate choice of class of mating partner plays a part. Perhaps birds that imprint in this fashion typically have inbreeding likelihoods that it is adaptive to overcome, or other kinds of mate choice problems that can be assisted by particular forms of learning involving imprinting. Such questions apparently have not been raised, and perhaps would not have been raised without the effort to think of appropriate limits on the concept of learning. Moreover, this way of looking at learning does not leave us with "no alternatives to learning" but "innate" and "hard-wired" or "pre-wired." Rather, it tends to lead us toward identifying different kinds of mechanisms alternative to the restricted definition of learning developed here. Perhaps most important, it stresses the adaptive significance of learning by describing the kind of environmental situation that is necessary and sufficient for its evolution.

\section{LEARNING AND MODELS OF KIN RECOGNITION}

Understanding kin recognition is the central "mechanisms" question in the adaptive (inclusive fitness maximizing) approach to social behavior. Contrary to implications by recent authors that evolutionists have not been searching for "design" mechanisms, the topic is far from being neglected. As is shown in the following review, it illustrates superbly the interplay between knowledge of behavior and the search for underlying mechanisms. It also bears on the above effort to discuss learning in adaptive terms.

Possible and probable mechanisms of kin recognition were outlined by Hamilton (1964) in the initial exposition of the concept of inclusive fitness. The subject has been pursued extensively and continuously on multiple fronts for more than a decade (Dawkins, 1976, 1982; Greenberg, 1979; Buckle and Greenberg, 1981; Crozier and Dix, 1979; Alexander and Borgia, 1978; Alexander, 1979; Wu et al, 1980; Holldobler and Michener, 1980; Getz, 1981, 1982; Ridley and Grafen, 1981; Waldman, 1981, 1986; Beecher, 1982; Grau, 
1982; Blaustein, 1983; Lacy and Sherman, 1983; Holmes and Sherman, 1982, 1983; Breed, 1983; Holmes, 1984, 1988; Sherman and Holmes, 1985; Gamboa, Reeve, and Pfennig, 1986; Fletcher and Michener, 1987; Waldman et al., 1988; Hepper, in press; and many more authors cited by these authors. Wilson $(1987$, p. 7) commented that ". . . rarely in the history of biology has a domain of empirical knowledge followed so closely and fruitfully upon an abstract theoretical idea."

Suppose that we apply the above restricted version of "learning" to the problem of understanding the mechanisms of kin recognition. First, it implies that the "break" between learned and other kinds of mechanisms for discriminating kin will occur between situations in which 1) different classes of kin are discriminated, or in which kin are discriminated from nonkin directly (i.e., when both are being encountered), and 2) every individual encountered is treated alike. Alexander (1979) referred to the second situation as "nondiscriminative nepotism". ${ }^{14}$ Two situations might be included. First, all individuals encountered may be treated with the same degree of beneficence, the correlate being that the species is divided into localized populations such that each individual typically encounters only close (maybe equally close) relatives (Alexander, 1979). Examples might be clones of aphids or sibling groups of caterpillars. Hamilton (1975) discussed this model under "viscous populations" (Table 1) (see also Crozier, 1987).

Second, Holmes and Sherman (1983) noted that "When relatives are distributed predictably in space, nepotism may occur as a result of behavior specific to a given location ... locations are recognized rather than conspecifics . . . and individuals' behavior varies relative to some reference point such as a nest site." Several examples of this situation are given from birds and treated under the label "spatial distribution." In other words, all individuals encountered in a certain region (such as around the nest) are treated nondiscriminatively (Table 1). If this mechanism is the only one it requires no danger of interlopers; if such jeopardy exists, then some additional mechanism must be used to prevent mistakes (Lacy and Sherman, 1983) and I would argue that it must be one of the learning mechanisms of discriminative nepotism described below.

In nondiscriminative nepotism, there is no involvement of correctable errors in kin discrimination per se, only in learning the characteristics and limits of the appropriate localities in the second case. Chances for correctable errors do occur, however, in all cases in which kin are actively (directly) discriminated from non-kin or in which multiple classes of kin are distinguished, as in humans. In all cases in these two categories, one might hypothesize (Alexander, 1979) that kin are recognized a) by learning (and subsequently using) traits of individuals with whom an actor has had particular prior experiences (direct learning or environmentally mediated recognition)

${ }^{14}$ Waldman et al. (1988) refer to this effect as "indirect kin recognition," but this term seems to confuse this situation with learning of traits later used to give preferential treatment to strange individuals with the same traits. See Table 1). 
Table 1. A Classification of Some Probable and Possible Situations and Mechanisms Involved in Certain Social Behaviors Requiring Preferential Treatment, such as Nepotism, Cooperation Between Parents, and Avoidance of Inbreeding

Phenotypic traits of other individuals are not required (learned. remembered)

1. Special behavior is nondiscriminative, displayed equally toward all associates, as might occur within separated, highly viscous populations such as groups of caterpillar siblings (Hamilton, 1964)

2. Special hehavior is site-specific, as in responses of various birds to putative young or mates at nest sites (Holmes and Sherman, 1982)

3. Special behavior is situation-specific, as with initial response (as opposed to later, learned responses) of mammalian mothers to newborns (Alexander, 1979)

4. Special behavior is a result of some combination of the above

Phenotypic traits of other individuals are used (learned, remembered)

Traits are learned

1. Only in special localities (as within the nest in eusocial forms)

2. Only in special situations (as when one learns a sibling by a parent's behavior toward it)

3. Only at special times (or ages, as with parents and offspring who either learn or reveal evidence of learning one another's identity just before the possibility of error appears through possible mixing of different broods (e.g., Holmes and Sherman, 1982)

4. Only if they are within a certain range of variation (e.g., it may be more difficult to learn a specific response to an individual of another species, or to a conspecific individual of the "wrong" age or stage)

5. Various combinations of the above

6. Without restriction (hypothetical only)

Traits are used (after being learned) only with respect to the actual individuals from which they were learned. (Note: this restriction is unlikely except when either learning is extremely precise or other potentially confusing individuals are not encountered in confusing situations; moreover, one expects learning to be extremely precise in the appropriate regards only when other potentially confusing individuals are regularly encountered)

1. Only in special localities

2. Only in special situations

3. Only at special times

4. Some combination of the above

5. Without the above restrictions

Traits are used on individuals other than those from which they are learned (remembered). (Note: This effect may be incidental as a result of faulty or incomplete learning or it may be an evolved adaptation. The more likely individuals are to interact with previously unencountered relatives in situations in which their phenotypes cannot be learned in any other fashion, the more likely this behavior, if it occurs, is evolved and thus adaptive; the less likely individuals are to encounter strange relatives the less likely they are to learn relatives precisely enough to avoid this effect as an accidental or incidental effect)

1. References are traits of prior social associates (different from those on which the memory is observed being used)

a. Including environmental features such as site, situation, timing, plus traits of prior social associates

b. Without requiring environmental features

2. References are traits of self

a. When association with a third party in a special situation creates an aceeptance or rejection choice involving two rather different possibilities (as when, in humans, a man attempts to assess probability of paternity of a child "acceptance or rejection by comparing phenotypes," Alexander, 1979)

b. Without requiring third parties ("self-referential phenotype matching," Holmes and Sherman, 1982)

In a specific situation (e.g., only littermates)

No specific situation (e.g., encountcring strangers anywhere) 
or b) by comparing phenotypes of novel individuals with those of other individuals with whom one has had different prior experiences and treating new individuals appropriately (indirect learning or socially mediated recognition). Thus, for a), a female may treat as her own off spring any individual with which she has a particular experience associated with parturition or hatching; a juvenile may treat as its parent the first moving object of a certain size, shape, or color that it sees after hatching or birth (Table 1); a sweat bee may treat as a sibling any individual present in its nest before it leaves the nest itself; a human may treat as a sibling any individual toward whom its mother or father, or both, behave in a certain fashion; etc. For b), a sweat bee may treat as a nestmate an individual with traits resembling those of nestmates it encountered prior to becoming a guard bee (termed "mediated recognition" by Holmes and Sherman, 1982); humans may use mannerisms, habits, speech, surname, even (in the modern, evolutionarily novel world) possession of a book with a family tree just like one's own, to help identify collateral relatives never before encountered. Humans may also use verbal cues or instruction from others. And they may use comparisons of their own traits with those of individuals with particular social associations with themselves (such as a male comparing to himself an offspring of a woman with whom he knows he has had sexual relations as a test of whether or not it might be his own offspring); etc. (Alexander, 1979). All of these have been regarded as learning situations, and they all obviously meet the criterion of involving correctable errors (see Holmes and Sherman, 1983; Sherman and Holmes, 1985; Fletcher and Michener, 1987; Waldman et al., 1988; and Hepper, in press, for reviews of cases of kin recognition).

In the rest of this review I wish primarily to consider two issues: 1) the extent to which social learning, especially without self-reference, can account for the kin recognition findings of different investigators with different organisms and 2) the differences between likely mechanisms in kin recognition involving beneficence and incest avoidance or other aspects of mate choice.

Sweat bees as imperfect social learners. Sweat bee females have been shown in the laboratory to use the phenotypes of other females with which they associate as newly emerged adults to determine which familiar and strange females to allow into the nest when they are guarding the entrance (for the precise conditions, see Greenberg, 1979; Buckle and Greenberg, 1981). I suggest that some parts of these experiments, those in which relatives (or relatives of associates) never previously encountered are treated in a special way and similar experiments involving other organisms, most likely are demonstrating evolutionary mistakes, absent in the field and engendered by laboratory situations. In fact, it would appear that sweat bees recognize relatives almost precisely as humans do, according to the social mediated learning model advocated by Alexander (1979). The surprising part of the results ("recognition" of relatives not previously encountered) may occur 
because sweat bees in laboratory experiments make more mistakes than humans, and mistakes of a sort that humans rarely make.

Any organism that learns who its relatives are, regardless of the means of learning, must remember their identity in order to treat them appropriately. This continued recognition is likely to be based on heritable variations in the traits used in recognition (Greenberg's, 1979, "innate components" of kin recognition), whether the organisms are humans, sweat bees, honeybees, ants, ground squirrels, or any social species; non-heritable variations, which are also used, are also likely to be more fickle and temporary (e.g., Mintzer, 1982; Linsenmair, 1987). Humans are so adept at remembering collections of traits that they almost invariably remember individuals (Wells, 1987), and almost surely have been strongly favored for doing so (and humans, in turn, have evidently been favored for being recognizable to other humans as individuals). Some organisms that also learn heritable differences in traits, but are less capable, may not remember enough to recognize individuals but rather remember traits or sets of traits that are not unique. As a consequence they may mistakenly accept strangers with many attributes in common with their associates, especially in novel situations. No evidence seems yet to have been presented that sweat bees are required frequently in the field to judge whether or not to allow strange sisters or other strange close relatives into their nests, which has been the test situation in the laboratory that has attracted the most attention and that has, ironically, caused investigators to believe that these animals have unusual abilities to recognize kin. If female sweat bees tend to oviposit only in a single burrow system, wild sweat bees are unlikely to encounter strange siblings. Even if sisters sometimes nest in different burrows in the same region, so that guard bees might be approached at nest entrances by cousins, they are unlikely to be favored for allowing them in if the alternative is their nestmate sisters.

According to the "imperfect social learning" hypothesis, the reason sweat bees are more likely to allow strange individuals into the nest that are more and more closely related to their nestmates (Buckle and Greenberg, 1981 , inbred the bees to different degrees to produce this result) is that they are less and less able to distinguish them from their nestmates because they have more and more traits in common, not that the guard bees are keener and keener about knowing who ought to be let into the nest on nepotistic grounds.

Despite widespread acceptance, then, that 1) sweat bees are behaving in an unusual or unexpected fashion when they show tendencies to allow strange relatives of their nestmates into the nest or statements that 2) it is unknown whether humans or other vertebrates can accomplish the same feats (e.g., May and Robertson, 1980), humans and sweat bees probably use the same mechanism, the principal difference being that humans are so much more complex and accurate about it that they have failed to understand the "mistakes" of other species.

Sources of reference in social learning about kinship. Holmes and Sherman 
(1982, 1983; also see Lacy and Sherman, 1983; Holmes, 1988; Reeve, 1989) refer to sweat bees' tendencies to treat unfamiliar kin of their prior associates as "phenotype matching"' and regard this label as identical to Alexander's (1979) "comparing phenotypes." Holmes and Sherman, however, include in "phenotype matching" situations which are increasingly being considered separately (e.g., most chapters in Fletcher and Michener, 1987 and Figure 1). They define phenotype matching as "an individual learns and recalls its relatives' [read "associates",'] phenotypes, or its own phenotype, and compares phenotypes of unfamiliar conspecifics to this learned "template", (Holmes and Sherman, 1982, p. 409). Sweat bees evidently do not use their own phenotypes in learning to recognize relatives, since individual bees that associate only with non-relatives later do not favor their relatives (Buckle and Greenberg, 1981).

Lacy and Sherman (1983), in trying to relate phenotype matching to Alexander's (1979) models, wrote (p. 506) that “As Alexander noted (1979, p. 116), the phenotype-matching mechansim '. . . does not require that the ability to recognize phenotypic attributes be conferred by the same genes causing the attributes, or that such abilities be used to make quantitative (as opposed to qualitative) judgments. Most importantly, it does not specify how the appropriate response to a particular phenotype is established; the judgment probably requires previous learning about one's own phenotype (or those of others) as well as about the nature or significance of the particular relationship being accepted.' "In this statement, however, I was explicitly referring back to the circumstance in which (for example) a man asks whether the child of a particular woman, with whom he knows he has had sexual relations, is his or not (Table 1). This situation is not the same as, for example, an individual encountering a stranger, recognizing him as a stranger, and then asking himself whether or not the stranger is some particular kind of relative, or even recognizing two strangers as such and then asking whether one is a closer relative than the other.

The two above situations represent opposite extremes. Anyone attempting to assess his relatedness to a stranger met outside any social context that might convey relevant information has nothing to use but his own phenotype and, at least in cases such as sweat becs, his memory of other associates (assuming he had had prior associations). The case involving paternity assessment has additional special attributes. First, the man can know whether or not he had sexual relations with the mother at approximately the correct time (it isn't necessary that he "know" this in the conscious human sense). Second, the child's relationship to the man is one of two quitc different possibilities: an offspring or a non-relative. The man may also know the other likely sexual partners of the woman so that he can extend his comparisons to include their attributes. The man meeting strangers would have no specific categories of relatedness to decide between.

Two kinds of situations used in experiments on kin recognition seem to fall between these two extremes. In the macaques studied by $\mathrm{Wu}$ et al. 
(1980), a juvenile in the field presumably would never encounter juveniles that were not members of its own troop (the limit of the relevant social situation). A juvenile ground squirrel (e.g., Holmes and Sherman, 1982, 1983) still in the nest presumably would not encounter any juveniles that were not full- or half-siblings. Older female ground squirrels, being philopatric, are also likely to encounter close relatives repeatedly. The macaque, being a single birth, would not have littermates with which to compare to a stranger, but it might have associated with an older sibling with the same father. All mammals, of course, associate with their mothers, and some with their fathers as well. These kinds of details about social systems (behavior) are important to the investigators of the underlying design of kin recognition because they specity the avenues of learning available to the animals.

Humans seem to have a tendency to attribute unusual or mysterious abilities in kin recognition to nonhuman species (e.g., May and Robertson, 1980). One reason may be that the investigators belong to a different species and use different sensory means to distinguish associates (making the test animal's behavior seem mysterious from the start). Another is that it is easy to interpret mistakes favoring socially strange relatives in test situations as evidence of unusually keen or complex kin recognition devices, rather than as evidence of imperfect learning or imperfect recognition devices; humans find it so easy to make distinctions that the animals are not making that they believe the animals are recognizing kin rather than failing to recognize prior associates. Failures to reject strange individuals with the attributes of prior associates can be favored by selection, but only if organisms regularly encounter strangers toward whom nepotism (or some other relevant social behavior) can profitably be directed. Otherwise, there is no reason to believe there has been selection for abilities to transfer learning from one social situation to another. Incidental tendencies to treat novel relatives preferentially would be expected simply because there would have been no strong selection to refine ability to learn about and remember traits of actual associates well enough to identify them as individuals and restrict preferential treatment to them.

Full-and half-sibling recognition in ground squirrels. Consider the apparent ability to distinguish between full and half sisters by females of Belding's ground squirrels (Sherman and Holmes, 1982; Holmes and Sherman, 1983; Sherman and Holmes, 1985) and related questions from laboratory results with cross-fostering (Holmes, 1986a, b; Sherman and Holmes, 1985). Holmes (1986a, b) and Sherman and Holmes (1985) attributed both sets of results to self-referential phenotype matching, meaning that the ground squirrels identify strange relatives and distinguish full and half sisters by comparing other individuals with their own traits. Sherman and Holmes evidently drew this conclusion partly because they could not imagine how learning the traits of siblings could lead to the results they obtained, and partly because they believed their data actually supported the idea of self-referential phenotype 
matching: "Indeed, phenotype matching was proposed (Holmes and Sherman, 1982, 1983) to account for kin recognition when cues based on rearing association were unavailable (e.g., paternal half siblings reared apart) or when rearing-association cues did not correlate accurately with relatedness (e.g., multiple insemination producing full and maternal half siblings that are reared together)" (Holmes, 1988, p. 405). Although Holmes' statement uses the general term phenotype matching (Table 1), it refers only to self-referential phenotype matching.

It is probably believed generally that there is no way a social learning mechanism other than self-reference could explain the tendency of females of Belding's ground squirrel to favor full sibling nestmates over half sibling nestmates (Holmes and Sherman, 1982, 1983): "The more obvious courses of social learning . . . knowing who the mother is, the family context, etc.will not serve here"' (Hamilton, 1987, p. 421). I suggest, however, that imperfect social learning has still not been eliminated in this case.

If most multipy sired litters of ground squirrels are unevenly derived from the different fathers (as Hanken and Sherman, 1981, indicate, giving an average proportion of seven juveniles from one father to three from the other), then females in multiply sired litters will be subjected to a preponderance of attributes inherited from 1) the mother (all littermates) and 2) the male with more offspring. This means that if their individual recognition of sisters is imperfect, then because full sibling daughters of the more successful father are present in the greater proportion, an incidental effect will be that the traits of the majority father will on that basis be potentially more important in remembering siblings who have been learned through association within the litter than will the traits of minority fathers. That is, traits of the majority father will be encountered more frequently or more continuously. Assuming either a gradual (cumulative) or a one-exposure learning process (even in the latter case the majority father's traits are more likely to be encountered), an incidental consequence will then be a (probably weak) tendency to favor full sisters over half sisters. Several additional predictions follow from this hypothesis, some of which seem contrary to any other hypothesis: first, some females will be expected to treat their half sisters better than their full sisters, and females who do this are expected to be daughters of the less successful father of their litter. Second, interactions between half-sisters who are daughters of the majority and minority father, respectively, are expected to be asymmetrical: daughters of minority fathers are expected to treat their half sisters from the majority father better than vice versa. Third, if females do not use their own phenotypes (as here hypothesized), then in litters evenly divided between two or more fathers when the test animal has been excluded, females will not distinguish full and half sisters (actually, in laboratory cross-fostering experiments, presence of the mother, which can never be eliminated in experiments with ground squirrels, creates an asymmetry of unknown significance or degree in numbers of related individuals in the nest when juveniles are cross-fostered so as to 
create symmetrical litters of natural and fostered offspring; it seems likely that the mother's phenotype is important, yet how it compares with the phenotypes of littermates or self, especially in different circumstances, remains unknown, also see below).

The interpretation suggested here accords with the results obtained by Sherman. Unfortunately, none of the three predictions of the imperfect social learning hypothesis can be tested from Sherman's data, since he could not compare any individual female's behavior toward her full- and half-sister littermates, respectively, but had to rely on mean rates of agonistic and cooperative interactions between selected full- and half-sister pairs. The only data that are even marginally relevant are Sherman's (1980) comparisons of reciprocal territorial incursions by neighboring females. These results indicate that interactions between sibling nestmates (which would potentially include some cases like those described above in the third prediction) are slightly more asymmetrical (as the imperfect learning hypothesis would predict) than either those between mothers and daughters or those between nonsibling non-nestmates.

Holmes and Sherman (1983) note that "The data from our cross-fostering experiment in the field ... a are consistent with this [self-referential phenotype matching] hypothesis because as yearlings foster sisters were treated more like half sisters than full sisters." Such a finding is also consistent with the hypothesis of imperfect social learning so long as crossfostered individuals are in the minority or spend less time in the nest than natural offspring. Although Holmes and Sherman report neither numbers nor proportions of individuals cross-fostered per litter in the field, Sherman (personal communication) indicates that typically only a single individual was accepted into a nest.

Self-referencing and recognition of paternal half siblings. Similarly, Holmes' (1986b) discovery for Belding's ground squirrel that strange paternal half siblings are distinguished from strange nonrelatives has been regarded as requiring self-reference. The tested ground squirrels were reared in litters of full siblings. Each female, then, was exposed to the attributes of her father throughout her nest life, and could well have favored strange paternal half siblings through imperfect social learning of the attribute of nestmates, without self reference being involved. In this respect, this result seems consistent with the hypothesis of use of father's traits via nestmates in distinguishing full and half siblings.

Influence of the mother. Holmes' and Sherman's results, both in the laboratory and in the field, suggest that prior social interactions as littermates cause female ground squirrels later to behave less aggressively and more cooperatively toward one another. However, as Holmes has pointed out to me (personal communication), the influence of the mother can never be eliminated. Thus, in the laboratory experiements, each female tested was 
reared either with her own mother or with a strange mother. Even in the absence of influence from littermates or traits of self, a female reared with her own mother might see a strange sibling as a relative. The female with which she was tested, however, reared with a surrogate mother, would see her own sibling as having no familiar traits.

Experiments with proportions of relatives in litters. Holmes (1986a) later conducted cross-fostering studies in which each female ground squirrel had different numbers of own siblings and nonrelated individuals in its litter. Contrary to predictions from the imperfect social learning hypothesis, he reported that proportions of siblings and nonsiblings in the litter with a tested female, even whether or not a tested female was the only member of her natal litter in a particular social litter, did not affect her tendency to behave agonistically toward a sibling or a nonsibling reared in another litter. His results were virtually identical for all of the different proportions of siblings and nonsiblings used. These results caused Holmes to argue that self-referential phenotype matching which he believed had already been demonstrated in Sherman's field results with full and half siblings and his own study of pig-tailed macaques (Wu et al., 1980), was the only possible explanation. These results of Holmes may seem surprising, because they suggest that amounts of time spent in the presence of siblings' traits, numbers of times exposed to such traits, numbers of individuals asociated with that carry the traits, or likelihood of encountering a specific trait, all of which would vary with proportions of siblings, are all irrelevant to learning and remembering how to respond to relatives. ${ }^{15,16}$ If either nestmates' or mothers' phenotypes were used, they would apparently need to be learned in a single experience, and not thereafter reinforced or altered. This would mean, however, that the first individual encountered during the necessary sensitive

\footnotetext{
${ }^{15}$ Comparisons of figures 1 and 2 of Buckle and Greenberg (1981) suggest that proportions of two different kinds of nestmates probably did affect sweat bees' acceptance of strange individuals of the two kinds; thus, when bees were associated in groups of six comprising three sisters from each of two different families, each set of three sisters accepted into the nest unfamiliar sisters of their associates from the other family at rates of $67 \%$ and $64 \%$, respectively; but when the association was five sisters of one family and one of the other, the five sisters accepted only $56 \%$ of sisters from the single individual's family while the single individual accepted $73 \%$ of sisters from the family of her five associates. Also, sweat bees evidently do not use their own phenotypes in learning to recognize nestmates (Buckle and Greenberg, 1981). Unlike ground squirrels, sweat bees are reared without influence from their mothers, since the mothers only place an egg and larval food in a tunnel within the nest burrow and then close that tunnel.

${ }^{16}$ In the experiments reported by Holmes (1986a), female ground squirrels spent up to approximately 72 hours with their littermates before being transferred. As Holmes notes, one may question whether this association is responsible for the lowered agonism between siblings reared in different litters as compared to nonsiblings reared in litters with one another's sisters. Holmes (personal communication), however, reports that in examination of his unpublished data he found no correlation between variations in times less than 72 hours actually spent with littermates and degrees of agonism. It is possible that most learning takes place quickly enough that he did not have the appropriate range of variation in times of association. On the other hand, Sherman's results with cross-fostered individuals in the field (Holmes and Sherman, 1982) suggest that tendencies to favor nestmates are not expressed in field situations until near the time of emergence from the nest, whether or not they are learned earlier.
} 
period would be extraordinarily important, and in litters of different proportions of relatives of different sorts the prevalent kind of relative would more likely be the first encountered. As a result, the only way to account for Holmes' results, as he has pointed out to me, is if matching with self were the only mechanism involved. It may seem unlikely that siblings' or mothers' traits, or both, are used in some situations and only self in others. Additional experiments are planned on these questions (Holmes, personal communication).

Evidence of self-referencing in other organisms. It seem possible that selfreferencing occurs as an incidental side effect of the evolution of capabilities to use the phenotypes of others in assessing relatedness. It might be surprising if such abilities did not exist, but it is important to conduct the kind of experiment that will distinguish between evolved and incidental effects. My view is that such abilities are unlikely to evolve in the context of nepotism, not that they are unlikely to exist. On the other hand, unless effects of self-reference were neutral or beneficial, which I do not expect in the context of nepotism, one would expect tendencies to self-reference to be disfavored and thus to be learning-resistant, in the context of nepotism (but not in the context of mate choice, Alexander, 1979).

Sherman and Holmes (1985) cite studies in which chickens were affected by their own phenotypes in later group and sexual interactions, but this happened only if 1) they were able to see themselves, as in a water dish (Salzen and Cornell, 1968) or 2) they were isolated for (up to 15) months (Vidal, 1982). Because single brief experiences can cause long-term imprinting in chicks, the conclusion we have to reach is that no bird or mammal has yet been shown to live naturally in a circumstances in which its own phenotype can possibly compete with those of its parents and/or siblings as a cue to grouping, and no unequivocal case of evidently evolved self-referent phenotype matching has been published. Alexander (1979) argued that the model of self-referencing without third parties suffers the same problems as the green beard model (non-beneficent alleles that produce the help-eliciting phenotype and disagreement among the genes of the genome, also see Blaustein, 1983). Queller (1985) argued that genes other than a green beard gene will gain from the action of a green beard gene because they are slightly more than randomly likely to be present in another genome with a green beard gene. The problem, though, is partly whether or not social learning situations exist that can set in place kin recognition mechanisms (e.g., social learning) that will enable non-green beard genes to outreproduce their alternates that must depend on green beard effects. To me that seems virtually inevitable.

Self-matching, kin recognition, and mate choice. As a result of preceding discussions we can now think of two contrasting situations in which to consider the likelihood of self-referencing: 1) self-referential phenotype match- 
ing when there is correlative information from variable social situations, when dramatically different classes of relatives are involved, and when the question is whether or not to dispense beneficence; and 2) self-referential phenotype matching when no information is available from variable social situations, relatedness changes according to slight gradations, and when the relevant question involves mate choice. After describing a system for distinguishing classes of relatives through building up a knowledge of one's own odors or visual appearance and that of relatives, Hamilton (1987, p. 422) wrote on this topic as follows:

... the proposed mechanism has no reason to stop at discriminating fullsiblings from half-siblings. Among full-siblings, for example, there are those who happen to have a more similar shake out of chromosomes from the parents and those who have less. Rather surprisingly, there is already evidence that human discrimination (here undoubtedly using many media besides smell) can discriminate among full-siblings (Pakstis et al., 1972). so long as the genes involved in all parts of the discrimination are well spread among the chromosomes, all genes except for the 'non-discriminator' allele that is being replaced, benefit from any action that fulfills the kin-selection criterion on basis of the estimated $r$. We need not expect that other elements in the genome will evolve to suppress the effect. The system of measuring similarity is quite different from one that reacts to a particular trait-i.e., a 'green-beard trait' (Dawkins, 1976; Ridley and Grafen, 1981) as will shortly be seen.

Hamilton's reference at the end of the last sentence is to a following discussion comparing kin recognition to immune reactions, sexual recognition, and outbreeding signals. I argued (Alexander, 1979, pp. 118-119) that sexual recognition signals and immune reactions are unlike kin recognition signals (as a criterion of beneficence-giving) in that intragenomic conflict cannot be engendered because the interests of all genes in the genome are alike. Although different genes may carry conflicting information about which phenotype is the best potential mate for the genome in which they both reside (i.e., one or both may engender a response that is "wrong" and hurts them both reproductively), their interests will be equally served by selection of the best possible mate, regardless how this is accomplished. Their "disagreement" would be a consequence of one of them making a "mistake." Contrarily, their interests will not always be equally served when the presence of either alone is used to select another individual as a target of beneficence, as in nepotism, because genes that can gain or lose through particular acts or nepotism recombine in different genotypes and gene effects can mimic traits so as to induce beneficience but never give it. Such "disagreement" is more likely to reflect an adaptive conflict of interest. This argument is the source of what Crozier $(1987$, p. 58) called " . . . the supposed greater complexity of recognition allele systems as against the phenotype matching systems (e.g., Alexander and Borgia, 1978) ..." which he says "is more apparent than real." Crozier notes that "the same locus may possibly encode both for transmission of a behavioral signal and its reception," and he cites Bentley and Hoy's work on the mating system of interspecific 
hybrids in Teleogryllus. It is a prediction of my argument that mating systems may be expected frequently to show such linkage but not systems of nepotism. The results of Wu et al. (1980) with pig-tailed macaques may also be relevant not to nepotistic beneficence hut to outbreeding.

Despite the arguments of Ridley and Grafen (1981), and Hamilton's tendency to view kin recognition and sexual recognition mechanisms as similar, I believe the above argument still holds. Moreover, 1 regard this point as so strong that if one discovers that members of a species are in fact able to distinguish closer and more distant relatives within a class, as suggested with full siblings among humans (Pakistis et al., 1972), this may be evidence that the ability is not an evolved mechanism of kin recognition, and probably is not used in that context (see above). The point that cannot be evaded in the "green-beard" problem is that there are more than two alternatives for the genes in a genome: one alternative is not to help anyone; another is to help anyone who carries any particular allele or set of alleles, regardless whether or not any other particular alleles are carried; and the third is to help only those who have some particular likelihood of carrying any gene in the genome, according to that likelihood. The third alternative obviously will work, when social beneficence is possible, and from the point of view of the genome as a whole, it is obviously better than the other two. The problem for kin recognition not dependent on social context, or solely through comparison with one's own phenotype, is to prevent the second alternative from being deleted because it either leads to intragenomic conflict via transformation to a green beard effect or is a poorer alternative than not to help, or-should it arise in a sexual recognition or other context-to prevent it from being replaced by a social learning mechansim. The mathematics suggesting that every allele gains if it has a slightly greater than random probability of being present in the genomes of both helped and helper individual (e.g., Queller, 1984) only work if one assumes that the involved alleles cannot be outcompeted by other alleles yielding greater benefits for themselves; if the evolution of kin helping is possible in the first place, then its tuning in the direction of increased benefit must also be possible-here via evolving toward a general and more or less even probability of presence of each allele in the helped individual.

The function of tadpole kin recognition. The various so-called kin recognition results obtained with tadpoles (see references in Holmes and Sherman, 1983; Sherman and Holmes, 1985; Waldman et al., 1988) remain puzzling to me. These studies may represent a particularly good example for the basic argument in this entire assay: that underlying mechanisms of behavior may not be understood, or even analyzed appropriately, until the probable selective value of the behavior they produce is known. The tadpole studies thus suggest a particular way of erring in studies of kin recognition, namely, believing that one is studying only kin recognition in the familiar context of how to be appropriately neopotistic, when in fact one is (either "instead" 
of "also") observing 1) "selfish herd" reactions (Hamilton, 1971) (efforts to stay in a group whether or not it is composed of relatives) and/or 2) mate selection precursors. Although both topics are regarded as parts of kin recognition (most chapters in Fletcher and Michener, 1987, and especially Crozier, 1987), I have been arguing that the same mechanisms will not underlie them. The tadpole results may actually involve all of the three phenomena of kin recognition, selfish herd effects, and mate selection (the last perhaps including inbreeding and outbreeding effects). It is crucial to distinguish the three, if no objection can be raised to "genetic" (nonlearning) models for mate selection and if self-referencing is more likely in the last case (see Alexander, 1979, pp. 116-121). Indeed, the manner in which arthropods and the lower vertebrates (fish, amphibians, reptiles) identify members of their own species, and of the opposite sex, as appropriate mating partners is, I believe, 1) not known or suspected in any case to involve social learning, 2) not demonstrated in any case to involve learning, and 3) utterly resistant to modification in the various insects where it has been studied most thoroughly (e.g., crickets, see Alexander, 1969). The ability is probably widespread among insects to live alone for their entire lives yet mate preferentially or solely with members of their own species. Amphibians, too, probably select mating partners (in the sense of conspecifics of the other sex) by systems that are virtually excluded as possible mechanisms for discriminative kin recognition (Alexander, 1979, pp. 112-115).

Many tadpole studies have measured how different individual tadpoles tend to remain close together in pans in the laboratory. The problem with the results is that we cannot easily predict what would be discovered with any species, or by comparing species, if not only discriminative kin recognition but also one or more of the following is involved (to one degree or another): 1) selfish herd effects, 2) nondiscriminative nepotism, and 3) mate selection. For example, we don't even know if a faint tendency to favor siblings when very young might be part of a system for rejecting mates that are members of other species much later in life, or a system of avoiding mating with close relatives, or even both.

Regardless of reasons for doubting any of the mechanisms indicated in Table 1, they all involve learning, and all apparently involve the possibility of adaptive mistakes that can be corrected by experience or learning. The same is not true of indiscriminate nepotism or the so-called "genetic model." The question is thus raised whether the hypotheses generated here about learning specify not only the situations in which learning is expected to evolve, but also situations in which non-learning mechanisms are not expected by an (ardent) adaptationist to prevail. For non-learned mechanisms by which kin and non-kin are discriminated (as postulated, for example, via histocompatibility alleles: see Waldman et al., 1988) do not represent situations in which correctable errors can be made. The question raised is this: If there are no learning situations preceding an association in which discrimination would be adaptive, then what is the likelihood that the animal 
has evolved a mechanism that will allow it to determine whether or not the associate is kin (or possesses some particular allele in common) and behave appropriately?

Obviously, I am not arguing that learning is not likely in selecting higher quality mates, at least in species in which there are certain kinds of repetitive interactions with prospective mates. But I am arguing that recognition of appropriate mates by class (conspecifics of the other sex) without learning is much more likely than kin recognition without learning. Hamilton has suggested (personal communication) that it is possible that a non-learned mate recognition or immune response mechanism can be used, at least temporarily, in the context of kin recognition (i.e., before the consequences of green beard effects deleterious to the rest of the genome can lead to its suppression). Nevertheless, such effects will be difficult to identify, because kin recognition can be employed not only in nepotism but in connection with adaptive outbreeding and inbreeding, where its consequences are more like those of mate recognition and immune reactions. (Interestingly, Yamazaki et al., 1988, have presented evidence from cross-fostering studies that, for inbred male mice previously shown to have ". . . a tendency to mate with females of an $\mathrm{H}-2$ type different from their own . . . there is no cogent reason to invoke any agency . . . other than chemosensory imprinting." This means, incidentally, that these animals are not, as might previously have been thought, using their own phenotypes to make comparisons with those of others.) Similarly, many of the results obtained with tadpoles that live in groups (see summary by Waldman et al., 1988; Waldman, 1988) may represent evolved responses that simply keep tadpoles in their groups or enable them to return there (as parts of "selfish herd" responses, Hamilton, 1971). This may even be true for tests that show differences in responses to full and half siblings of various sorts, particularly since 1) in some species half siblings and unfamiliar siblings are not likely to be encountered in the field (Waldman et al., 1988) and 2) it is possible for results from mechanisms for staying in a group for selfish reasons, as with results with unfamiliar siblings or relatives of nestmates in sweat bees (above), to give deceptive effects suggesting the presence of adaptive kin discrimination in laboratory experiments.

Honeybees. The above review is most deficient with regard to work on honeybee nestmate and kin recognition. Although the experiments are extensive and complicated (Getz, 1981; Getz and Smith, 1983; Breed and Bennett, 1987; Getz, in press), none of this work unequivocally demonstrates use of self in a way that suggests evolved kin recognition or excludes imperfect social learning. My primary reservations have to do, first with the same caveats Getz (in press) lists (p. 25) and, second, with the problem of who feeds larval bees that are later tested (as adults) for abilities to recognize kin in different situations. Unless it can be demonstrated that bees do not respond preferentially to the traits of their nurses, associative learning seems 
to remain as a possible mechanism for discrimination of both full and half siblings and paternal half siblings in honeybees. In this regard, it is intriguing that worker bees in some experiments favor relatives (previously unencountered as adults) in regard to food transfers but not in regard to agonistic interactions. Getz and Smith's (1983) report that workers reared with only full sisters could then discriminate full and half sisters is consistent with an imperfect social learning hypothesis, as is the ancient apicultural practice of removing the old queen and substituting a new queen unrelated to the workers, by presenting her in a cage with a few of her own workers and an access hole plugged by candy that will take the resident workers a day or so to remove (also see Breed and Bennett, 1987). Even if nurse bees represent both full and half siblings to juveniles, it seems necessary to determine who feeds whom, and eventually to discover the ultimate origins and modes of transmission of any biases.

Conclusion. Kin recognition mechanisms obviously represent an extremely complex and involved set of proximate mechanisms of social behaviors. Regardless how the conflicts among current hypotheses are eventually resolved, the extensive work being conducted with diverse species of social animals seems the paradigm example of how profitable investigation of adaptive behavior and its underlying mechanisms can be conducted in concert. In setting out his theory of inclusive fitness, Hamilton (1964) provided biologists with a set of intellectual challenges with respect to underlying design-the adaptiveness of learning and development in the recognition and classification of other individuals - that has yielded a parallel to the last half century's "Great Debate" of population genetics over the evolution of dominance and recessiveness in genes (e.g., Wallace, 1968).

\section{LEARNING, CONSCIOUSNESS, AND THE HUMAN PSYCHE}

Turning explicitly to questions about underlying mechanisms in the functioning of the human psyche (also see Alexander, 1989), I would propose that four of its aspects, cognition, linguistic ability, the emotions, and personality traits, in general involve learning mechanisms that typically are not (and sometimes absolutely are not) available to our consciousness (the fifth aspect). This is so, I suggest, either, first because they involve primarily procedural knowledge (Kihlstrom, 1987), which, if conscious, would use expensive conscious time without contributing sufficiently to appropriate uses of knowledge, or second, because they involve knowledge used in deception or manipulation partly through the vehicle of self-deception (Trivers, 1971, 1985; Alexander, 1979, 1987a, in press). Along with Humphrey (19831986), I see consciousness as a special way of dealing with immediate social circumstances by being aware, and, moreover, as the system by which pro- 
jections to future situations of a particularly useful sort are accomplished (that is, via planning, foresight, scenario-building, etc.). Consciousness at least mimics the "general-purpose" or "domain-general" mechanisms that Cosmides and Tooby (1987) conclude are not important as broad explanations of the guiding forces underlying human behavior. I say "mimics" because it is possible to argue that consciousness or its functional context (here argued to be social interaction) is itself, in some sense, a domain-specific context or activity. Consciousness continually refers us back to the (usually social) situation at hand, continually using current circumstances, coupled with others that we may recall from our memories, to deal with immediate and future situations. The social situations that seem tied to consciousness, and the manners in which we must deal with them if we are to serve our interests, change continually, before our eyes, so to speak, so that the strategies necessary to deal with them must also change continually. This is the aspect of sociality that conscious awareness seems especially equipped to manipulate. The nature of consciousness, moreover, seems to dictate that its manner of serving our social interests is general purpose or domaingeneral, in the sense of involving continual changes of strategy or tactics, depending on what our social competitors and cooperators are doing.

Rozin (1976) argued for an "increased-accessibility" view of the evolution of intelligence, which, he suggested, contrasts with the "general-process" view. He saw the evolution of intelligence as in part a process of making "adaptive specializations" "more accessible to other systems and, in the extreme . . . [conscious]." He also suggested that "part of the process of learning and education can be considered as bringing to consciousness some of the limited-access programs, the 'cognitive unconscious,' already in the head." (p. 246) In some sense this "superficiality" of consciousness, or this "accessing" facility, is deceiving to us in regard to its seeming comprehensiveness, in the manner of Jaynes' (1977) lighted flashlight looking to see if every corner of the chamber it is in is dark. If we are not aware of (conscious of) the cognitive unconscious, we can scarcely be aware of its vastness and its complexity.

Rozin's view of consciousness seems to parallel the notion of "finder" or "directory" computer program, in which fragments of information from the cognitive unconscious are used as labels to retrieve packages of information needed to deal with the current situation. I wish my own argument to go beyond this view (which, however, seems to me appropriate and intriguing as far as it goes). The view of consciousness and its use in scenariobuilding that $I$ favor is one that uses a "finder" kind of program to access information from, say, the cognitive unconscious, but then, perhaps more important (or more central to my concern), in turn uses the information so accessed in special ways, via scenario-building, to deal with social eventualities (as, perhaps, in a "multi-finder" program which allows one to deal with material in several different programs at once, so as to construct novel combinations). 
The "domain-specific" or "adaptive specialization" view of learning has led to criticism of conditioning experiments that utilize stimuli chosen without respect to the animal's "developmental niche" (Johnston, 1982b). Thus, Johnston (1982b) remarks that "The use of arbitrary tasks to cxclude instinctive abilities from experiments on learning implies that learning is to be treated as a general purpose ability, one that functions equally well in any environment that respects only a set of rather gross physiological and morphological constraints on the learner's behavior ... [however] if the general purpose nature of learning is not assumed, the use of arbitrary tasks becomes indefensible."

Rozin's view, however, to which I am sympathetic, is slightly different:

One could be led to conclude, as Schwartz (1974) has suggested, that 'It is odd, but perhaps reaassuring, to think that by studying the behavior of pigeons in arbitrary situations, one learns nothing about the principles which govern the behavior of pigeons in nature, but a good deal about the principles which govern the behavior of people.' The Skinner box presents a type of 'abstract' task in which 'emancipated' humans can perform well, since they can apply many programs over a wide variety of situations. Strangely enough, then, the adaptive specialization notion leads to a definition of intelligence along the lines of concrete (limited, specific applicability) to abstract. This concrete-abstract dimension is reminiscent of what many psychologists mean by intelligence.

One can also see that all interactions with other living forms, such as Cosmides and Tooby's (1987) example of "when a tiger bounds toward you", which, even if parallel, are infinitely simpler than those involving "when a conspecific social competitor tries to outwit you," call for immediate domain-specific underpinnings. Nor is there any reason to deny that there must be at least as complex a hierarchy of domain-specific mechanisms underlying consciousness as underlies any other aspect of behavior. It seems possible, however, that the particular nature of human consciousness, as I have been trying to describe it (including its misleading appearance of being central, deep, and comprehensive in our mental activities), is involved in the widespread belief in the importance of "domain-general" or "general process" kinds of learning and strategizing.

Consciousness, then, may be a system not only for accessing and reaccessing certain kinds of information that we are going to use primarily in social circumstances, but for developing their use. This argument requires that some of the contexts in which humans use consciousness now be unable to account for its evolution. Examples are learning to type or play a musical instrument, or to decide which tool is appropriate or how to make some particular tool. Tool use may appear to be the principal competitor for the argument that only social interactions can account for the evolution and maintenance of human scenario-building (Humphrey, 1976, 1986; Alexander, $1979,1989)$. One question, however, is whether or not tool manufacture and use were generated to solve food or social problems (Wynn, 1988). Another is whether scenario-building (foresight, planning ability) evolved in connec- 
tion with tool use, or evolved in some other context, and then was expressed or used in connection with tools.

J. L. Gould (1986) uses the term "cognitive trial-and-error" for a kind of planning or purpose, or "higher-order learning," for "neural constructs by which animals in some sense 'think' about the problem, evaluating behavioral alternatives or formulating a 'plan' of sorts . . ." He regards cognitive trial and error as widespread in nonhuman organisms and not restricted to social interactions. He believes that it "would not seem to require consciousness, though awareness might on the one hand facilitate it, or, on the other, create behavior which, though as automatic as egg-rolling or stinging, might easily be mistaken for consciousness."

\section{CONSCIOUSNESS AND SOCIAL RECIPROCITY}

A central value of my arguments, if they are at least partly correct, should be in explicating the elaboration and maintenance of social reciprocity (reciprocal altruism: Trivers, 1972), defined (here) as successive reciprocal contributions to (or investments in) one another's inclusive fitness, with resulting temporary losses in own inclusive fitness, by two (or more) social interactants, in which all participants ultimately gain in fitness relative to nonparticipants. Social reciprocity thus is expected to evolve only when each contributor's investment is repaid with interest. Social reciprocity may be extensive and elaborate only in the social interactions of humans, where it is certainly more extensive and elaborate than in any other species. It is demonstrated only with great difficulty in nonhuman species, and, as Connor (1986) has noted, is typically confused there with mutualism and pseudoreciprocity (the latter being social investment with a net temporary cost followed by a return with interest to the original investor as a consequence of "selfish" or non-investing behavior on the part of the original beneficiary).

I believe that social reciprocity is unlikely in the absence of conscious purpose, planning, or scenario-building of the sort that we know humans engage in more or less continually, particularly in connection with social interactions.

Authors like Shepard (1984), when describing the usefulness of mental processes like dreaming and scenario-building in solving problems, typically list only outcomes relating to tool use (lowering a golf score by imagining a new grip, mentally devising a new one-handed method of tying sutures in an abdominal operation. etc.) or some kind of cognitive mapping, again raising the question whether such uses might not be the context of evolution of the scenario-building capacities of humans. I don't believe so (Rose, 1980, 1983; Wynn, 1988). By far the most difficult, uncertain (but with this quality amenable to alleviation through immediately prior contingencies), and multiple-option events involving potentially extreme costs and benefits to humans are social interactions (Humphrey, 1976-1987; Alexander, 1979-1989). 
All other kinds of hostile forces in nature have been dealt with by nonhuman organisms, probably repeatedly, using something other than the human kind of consciousness. The actions of other humans are the most severe tests of our abilities to look ahead and be prepared for any contingency. Moreover, social conquests or accomplishments are not as likely to be paraded (remembered, emphasized, broadcast) as examples such as tool use because of the way humans view evidence of motivations in others to "win" socially and to use their wins (through advertising them) to win again or further.

Finally, what is unique about humans is not their use of tools (although their extensiveness and complexity of tool use is obviously unique), not their ability to map cognitively the physical environment (either geographically or temporally), and not merely social cooperation as such, whether in food securing or other similar contexts (e.g., Cosmides, 1985). Rather, it is the combination of social cooperation for the purpose of competing with other conspecifics, and the resulting extensiveness and complexity of social reciprocity. These aspects of human sociality, which, as a combination, may be shared only with chimpanzees, in turn, I see as evolving because of the unique significance of intergroup competition in human sociality and evolution, this feature in turn deriving from the combination of ecological dominance and complexly cooperative sociality in the human species (Alexander, 1989 , in press). Only this combination, moreover, can account for any degree of extremeness in both elaborateness and centrality of social reciprocity and the accompanying (and required) intellectual capabilities (that is, any extent of departure of humans from other species in these respects).

Social reciprocity, as defined above, may be restricted to humans and a few similar primates (such as chimpanzees). The difficulty in even discussing the possibility of its existence in nonhuman species, or of demonstrating it there, may derive in part from the necessity of describing it in terms of human abilities to build scenarios and examine options likely to be available in the future. Mistaken assertions or inadequate demonstrations of its supposed presence in nonhuman species often depend upon unjustifiably anthropomorphic accounts of behavior, probably because the existence of social reciprocity depends upon human or human-like mental attributes that are both difficult to demonstrate and all too tempting (and easy) to invoke.

J. L. Gould (1986) secs the ability of "cognitive trial and crror," which appears to be a simple form or parallel of scenario-building, as widespread among nonhuman species, but he also describes it as taking a form primarily useful in cognitive mapping of localities and tool use. As already noted, my arguments about consciousness imply that the extensiveness and complexity of tool use in humans, and conscious mapping of motor tasks outside social contexts, are capabilities that arose secondarily and incidentally as a consequence of the evolution of complex scenario-building in social contexts.

These arguments beg the question of the likely precursor of the human kind of social reciprocity and scenario-building. This precursor might be 
construed to be an environment and an organism characterized by many uses of pseudo-reciprocity, defined as situations in which one social partner is selfish throughout the interaction, never taking even a temporary net cost through social investment in the other (Connor, 1986). But pseudo-reciprocity does not necessarily call for long-term interactions, for complex and repeated weighing of investments, or even (always) for close attention to the other party and its investments by both interactants. Accordingly, 1 would rather argue for a background involving a long-lived, extensively nepotistic species in which multiple relatives repeatedly invest in one another's inclusive fitness (the payoff from nepotism coming from increases in the inclusive fitness of the recipient of nepotism rather than from return investments in the nepotist). Such long-term patterns of alternating nepotistic investments virtually take the form of social reciprocity and can come to involve it, perhaps at first as a kind of "icing on the cake." Moreover, this particular kind of nepotistic investing seems to me to require the same general kind of mental equipment as social reciprocity, therefore to prime for the evolution of social reciprocity in every way. It seems to me that an ancestor with this kind of behavior is also very likely for humans (and chimpanzees: see references and discussion in Alexander, 1989).

Broad-scale accessing (to consciousness) of the sort suggested by Rozin (1976) may be what allows us to call up multiple strategies from multiple social contexts and use them appropriately. Adopting his scheme, we might suggest that special artistic, musical, linguistic, or other abilities might be special capabilities to "access" (to the general-purpose aspect of consciousness) certain relationships. Conversely, difficulties with the "languages" of mathematics or chemistry might represent special difficulties in accessing certain relationships. Some features of human activity, e.g., dyslexia and the extraordinarily rich abilities (but often quite narrow) of individuals known as particular kinds of "savants", might be special forms of inaccessibility that simply affect what seem to be more central or handicapping aspects of our lives in modern circumstances (cf. Velutino, 1987).

The general view I am advocating here, especially the argument that consciousness evolved in social contexts, seems consistent with the idea of "procedural knowledge" heing unconscious, and with at least some views of the conscious developed by those examining it in relation to cognition (e.g., Kihlstrom, 1987). (I speculate that this is why I am so negative toward most computers yet so positive toward the MacIntosh, because the MacIntosh requires virtually no burdening of the conscious with learning and remembering of procedural knowledge.) It may become useful in extending the view that approaches to explaining the human psyche that depends on artificial intelligence and the computer analogy eventually fail because the computer lacks self-interest and the possibility of deception, self-deception, and social manipulation; hence, the computer lacks any analogue of consciousness. In effect, the computer is an extension of the cognitive unconscious of the human brain, and is so used by the conscious operations of 
the brain, which perhaps continue to resist analysis precisely because of the manner in which it uses the cognitive unconscious. Rather than being programmed utterly and completely around its own self-interests, the computer is programmed in a fashion paralleling that of our domestic animals. We select the psyches (and other features) of domestic animals continually so as to serve our interests in various ways, depending on the particular animal and its uses. We select them to serve their own interests only by serving ours, so that in effect they have no separate interests (Darwin said that we have selected dogs to return our kindnesses with interest).

Computers start out with no interests of their own and are continually selected so as never to have any. Self-interest, and its consequences in respect to the psyche, are not merely a matter of complexity; they are a matter of organizational form, and of a dialectic between the nature of information and its possible uses, always in terms of the costs and benefits to one party, the self. In my argument, moreover, self is always seen in relation to other conspecific parties (i.e., the function of consciousness is social).

Thus, I see "'self' as consciously important because consciousness is a way of calculating how to serve self's interests explicitly when the obstacle to doing so is other selves with whom one must compete, sometimes by cooperating with still others. Self's interests can be advanced sometimes by adjusting how self is seen by others, through first observing the perception of self by other through self-consciousness (also see Alexander, 1989). Kihlstrom (1987) states (pp. 1450, 1451):

One thing is now clear: Consciousness is not to be identified with any particular perceptual-cognitive functions such as discriminative response to stimulation, perception, memory, or the higher mental processes involved in judgment or problem-solving. All of these functions can take place outside of phenomenal awareness. Rather, consciousness is an experiential quality that may accompany any of these functions. The fact of conscious awareness may have particular consequences for psychological function-it seems necessary for voluntary control, for example, as well as for communicating one's mental states to others. But it is not necessary for complex psychological functioning . . . for ongoing experience, thought, and action to become conscious, a link must be made between its mental representation and some mental representation of the self as agent or experiencer-as well, perhaps, as some representation of the environment in which these events take place.

\footnotetext{
O wad some Pow'r the giftie gie us

To see oursels as ithers see us!

It wad frae mony a blunder free us, And foolish notion:

What airs in dress an' gait wad lea'e us, And e'en devotion!
}

Robert Burns

This essay was begun as a consequence of reading Cosmides and Tooby (1987), and following a lengthy and useful exchange with Donald Symons of the University of California, Santa 
Barbara (begun orally in the spring of 1987, and continued in correspondence). It was aided by discussions in Biology 494, Human Behavior and Evolution, and a graduate student scminar or kin recognition, learning, and the nature and distribution of social reciprocity at The University of Michigan. Gerald Borgia of the University of Maryland, Cynthia K. Sherman, and Paul W. Sherman of Cornell University. Randy Thornhill of the University of New Mexicn, Leda Cosmides and John Tooby of Stanford University, Bernie Crespi of the University of New South Wales, Daniel Otte of the Philadelphia Academy of Natural Sciences, William Irons of Northwestern University, Napoleon Chagnon of the University of California Santa Barbara, and Laura Betzig, Paul Turke, David Buss, Robert Smuts, Beverly Strassmann, Richard C. Connor, and other members of the University of Michigan Evolution and Human Behavior Program also contributed to the thoughts expressed. Norman Kemp of the Department of Biology of the University of Michigan helped with the background of the concept of epigenesis. Ann Heise and Aina Bernier of the Department of Biology, University of Michigan, deserve thanks for helping with both the ideas and the literature. I am especially grateful to Warren $G$. Holmes and Paul W. Sherman for reviewing the manuscript repeatedly, and for tolerating with patience and kindness my dense prose and my endless questions about their kin recognition results. Despite the critical nature of some of my comments they have always helped me freely and in good humor. As a result our joint efforts to understand how kin recognition really works became an enjoyable intellectual exercise. Finally, I am indebted to Harvey Wheeler and several anonymous referees who provoked me constructively. and thereby helped me immensely in clarifying my arguments.

\section{APPENDIX}

\section{Heritability and Adaptiveness}

"To be an adaptation a trait has to be heritable."

What does this prevalent assertion mean? Is it sensible and correct, or confusing and irrelevant?

First, the statement is a kind of shorthand that sometimes leads to misinterpretation. Here is one way to expand it: "To represent a history of natural selection, differences in the expression of a trait must be owing to genetic differences.",

By this expansion the assertion appears false. Consider environmentally modified traits of any kind: calluses, learning, body size, muscle or tendon volume and strength, chest capacity, etc. The variations themselves are not heritable: they are owing to differences in the environment of different organisms or the same organism at different times. But the patterning of the variations certainly can cause them to be adaptive, indeed, it is almost certain to reveal this effect. Calluses appear in epithelial tissue that is stressed by wear or abrasion, and thereby protect it from further damage; learning is evidently patterned to enable organisms to correct errors, such as placing one's hand in a fire or inadvertently entering the (subsequently identifiable) lair of a predator; muscles, tendons, and chest capacity change in response to increased exercise, precisely in the direction causing them to be better suited to the activities being pursued; body size increases when food is abundant, allowing reserves to be accumulated and leading to accomplishments of strength, dominance, or response to enemies unavailable to those of smaller body size. Reverse effects in most of these cases can in the same 
way be seen to be at least potentially (and are eminently likely to be) adaptive: thin epithelial tissue is presumably less expensive and also is more flexible and tactually more sensitive; excessive muscle or tendon development is also expensive, and at least sometimes interferes with speed and certain kinds of agility; small body size is advantageous when food is scarce; etc. Learning may seem the most difficult to understand in this light, but the ease with which we lose unused learning, the probability that one kind of learning may interfere with another, and the probability that capacities for learning and remembering are limited all suggest that even here both directions of environmentally induced variation are adaptive.

For refutation of the original statement, of course, one needs only to demonstrate that environmentally induced phenotypic variations, that are legitimately termed variations in traits, can be adaptive, not that they are.

In the case which prompted this essay, the author of the above statement was referring to such differences as 1) body size within and between species on a north-south axis, thus to whether or not an adaptive explanation such as Bergmann's Rule could legitimately be invoked, and 2) jaw muscle volume differences in the same and different mammal species burrowing in different soil types. He might have wished to expand his statement differently, perhaps this way, "To be an adaptation, a trait must have a genetic basis." But this statement is not helpful, since all traits have genetic bases: there is no way to produce any part of an organism except by the interaction of genes and environment. Accepting this expansion of the original statement would mean that one can essentially ignore the requirement of heritability because it is always met. Moreover, this expansion of the statement would actually suggest an crror (a common onc), which results from a confusion about the meaning of "heritable," and is a frequent consequence of the genetic shorthand illustrated above. The genetic backgrounds of traits are examined, analyzed, and understood only via variations in the traits (even if molecular biology may someday change this). The genetic basis of a trait lacking in variations cannot even be identified. Accordingly, when anyone asks if a "trait" is heritable he doesn't mean "Is it genetically based?" but "Are the variations in this trait owing to genetic variations?" Or, possibly: "Are the differences between this trait and other traits owing to genetic variations?" Even environmentally induced trait variations such as in calluses, learning, and all the others described above also "have a genetic basis." That is, they are possible only because the organism possesses certain sets of genes. In this case, indications of the existence and complexity of the genetic basis may be available to us from the patterning of the variations in relation to environmental variations. For example, learning is probably never a "blank slate" phenomenon: apparently all organisms tested learn some things better and faster than others. Even if different organisms did not differ in this regard or we were restricted to looking at one uniform population of a single species - for example, humans-we could compare the patterning of actual learning variations against a "blank slate" model and 
from the comparison infer some things about the probable adaptiveness of learning (meaning both the underlying potential and its actual expressions, although everything we learned about the former would come from information about the latter).

If one assumes that trait variations are at least potentially adaptive, then the most useful information about them to test the question of actual adaptiveness is not their heritability but whether or not 1) the difference between two expressions of a trait is complex (implying not that the variations are owing to genetic variations but that the existence of the variations is owing to a substantial history of genetic change) and 2) each different expression of the trait appears to serve the well-being and (ultimately) reproduction of its particular bearer, in the particular environment in which it is (and, by inference, has been) living, better than any of the alternatives.

The patterning of trait variations suggested in the second of these two questions implies that phenotypic plasticity is rarely just a matter of "slop" between gene action and ultimate phenotypic expression (therefore, a failure of adaptation). Although this "slop" view of phenotypic plasticity has been prevalent in some circles (for example, those who have steadfastly believed that if something is learned it cannot legitimately be related to a history of differential reproduction; perhaps such people are confused on this point because of the existence of traits that do not vary as a consequence of environmental fluctuations, at least in ways yet measurable), it carries in it a certain naivete about the concept of phenotype. Thus, there is no reason for phenotypes (organisms, traits) to have evolved-no reason for genes ever to make any product but another gene-except that they thereby create graded or alternative responses to graded or alternative environments. If environments did not vary in ways that genes could respond to adaptively by making phenotypes (which means "by being plastic") there would be a continual tendency for life to revert to a condition of naked genes entirely lacking in phenotypes.

If 1) either heritable or nonheritable differences are complex (for example, the differences between the stridulatory files or the song patterns of two different species of crickets), this complexity alone makes it parsimonious to assume that they are owing to a substantial history of genetic change, therefore that selection was involved (because selection is virtually inevitable when genetic change occurs over any substantial period of time), hence that they are (their changes) adaptive. If 2) environmental effects on nonheritable trait variations can be shown to cause them to be more reproductive for their bearers than alternatives produced in other environments, especially when those environmental variations can legitimately be inferred to be the ones experienced during the organism's recent history then our confidence about the adaptiveness of the variations is further elevated. The combination of these two aspects of traits is all that can be meant by "evidence of design by selection." There are no other ways to determine adaptiveness. 
There is one more possibility of a way out of the arguments posed above, and that is for the supporter of the original statement to insist that traits must be defined in such fashion as to exclude environmentally induced variations from the concept of "variations in traits," and claim that the only "trait" involved in calluses or learning or the other examples listed above is the underlying ability to produce environmentally induced variations, in other words, to insist that the only trait involved in calluses is the (presumably evolved) potential of an organism's epithelium to produce variations in its thickness of the sort we term calluses, not the calluses themselves or even the pattern of their production. In this case the original statement (above) would be applied solely to differences between organisms in their underlying ability or "design" to produce calluses-amounts of callus or patterning of calluses. The actual patterning of calluses would not be referred to as adaptive, only differences in the potential for such patterning, revealed, nevertheless, only through studying differences in actual patterning of calluses. The concept of adaptive patterning could in this way be restricted to heritable differences.

Similarly, one could consider only differences in abilities to learnspeed or ease of learning different things at different times or in different circumstances. In this fashion all trait variations that are environmentally induced would be eliminated from the discussion of "adaptation," even though the only way to study underlying phenotypic potentials (adaptive designs) is to examine and evaluate the significance of their outcomes (such outcomes are what causes the underlying potentials to persist, disappear, or change).

While I regard all useful efforts to identify, characterize, and understand the actual phenotypic potentials that evolve through natural selection as extremely important, to follow the direction of definition I have just outlined in discussing adaptive or reproductive significance would restrict us, in the case of, for example, body size differences, to those differences demonstrated to exist when environmental conditions were rendered identical, as in a laboratory experiment (in other words, to differences known to be heritable); in effect, field-observed differences (those in the environments of selection, but for which heritability is unknown) would become irrelevant. The reason for the restriction would not be an effort to refine the concept of adaptation, or to deal better with which expressions of the phenotype have been saved because they have influenced reproduction favorably (as the original statement strongly implies), but rather an effort to locate and understand heritability and to define "trait" for purposes other than to understand adaptiveness. Heritability is a difficult concept that deserves attention, but probing its nature is not the only way, and most likely not the best way, to discover reproductive significance or infer its history. How to define trait is also a useful question, primarily in the context of how natural selection and the vagaries of genetic fate have managed together to organize and divide up the organism (that is, how the particulateness of heredity 
relates to the unitariness of ontogeny); it affects studies of adaptation in the sense that it bears upon how hereditary and ontogenetic contributions to the phenotype lead to the ultimate expressions of the phenotype. Adaptation includes the question of how actual expressions of the phenotype (not merely phenotypic potentials) maximize reproduction and how they are designed to do that.

Although it is obviously possible to place the kind of restricted meaning I have just described on the notion of adaptation, for adaptationists it seems to serve little purpose except to require the creation of new vocabulary, and, incidentally (I hope it is always merely incidental), to denigrate most, including, in my view, all of the best, published studies relevant to evolutionary adaptation, as the concept is currently treated by those most directly concerned with the effects of natural selection. There seems to be an opinion that restricting the concept of adaptation to "heritable" traits is a matter of cleansing biology of a lot of careless thinking about natural selection. This notion may have been generated partly because some groups of biologists were studying ontogenies and morphologies, and tried to figure how legitimately to divide up the phenotype so as to use it for purposes such as inferring branching sequences (actually, how natural selection and the other processes of evolution have divided up, or organized, the phenotype). For such people, environmentally induced trait variations would simply represent trouble, a source of confusion and possible error. Adaptive (reproductive) significance would be secondary to their interests, even though they might be able to convince themselves that the traits on which they ultimately focused were the real adaptations of the organism because they would be trying to be certain that traits as they studied them had firm and irrefutable ontogenetic and morphological (hence, genetic) underpinnings. In other words they might feel that they were "closer" to the things that were actually being saved by selection (I hope it is clear by now that in one way they would be, and in another way they would not). For their purposes it might seem appropriate to eliminate from consideration all environmentally induced phenotypic variations; indeed, the current environment is irrelevant to their interests, they are entirely concerned with inferring effects from past environments. The same view, however, is not likely to generate among those who concentrate on trying to understand how selection affects the phenotype with respect to reproductive effects. For these people environmentally induced trait variations-phenotypic plasticities-are necessarily the initial and central source of information.

There will probably always be difficulties in intellectual cross-fertilization when diverse groups of biologists try to make words mean strictly what causes them to be most useful for each of their own endeavors. Disagreements based primarily on language are especially unfortunate when the basic question is not language but the problems of understanding such astonishingly complex issues as (in this case) the raison d'etre, the ontogenetic unfolding, and the reproductive significance of the phenotype. Traits (and the 
environment) are ultimately our only sources of insight into these problems, and traits are, after all, expressions of the phenotype. Phenotypes are the diverse outcomes of what actually happens in nature at all stages of development; they are not merely potentials. Moreover, phenotypic expressions relevant to evolutionary adaptation are not typically produced in the laboratory, and are not easily identified as adaptive except in the field. Natural selection creates adaptations by its effects on ultimate phenotypic expressions; and the potentials that give rise, ontogenetically and otherwise, to those expressions are saved, lost, or modified as a result of the way ultimate expressions of the phenotype (environmentally induced or not) fare in natural environments.

One group of biologists, behavioral ecologists (some have called those who focus on humans "Darwinian anthropologists"), begins with observations on the reproductive significance of phenotypic outcomes and works "backward" toward the interaction of genes and phenotypes during ontogeny in the setting up of those phenotypic outcomes. A second, more recently generated group (those who work with humans call themselves "Darwinian psychologists") believe that they are more concerned with ontogeny and physiology (underlying design of adaptiveness) than the first group; they concentrate on trying to study the details of learning mechanisms and such things (but they too, of course, have to begin with behavior and evidence of its reproductive significance). A third group (of biologists) begins with morphologies and physiologies that underlie ultimate (usually behavioral) phenotypic expressions and also works toward understanding ontogeny and the makeup of the whole organism, but for the purpose of tracing evolutionary pattern more than process. In the end we'll all have to learn to be tolerant of one another's approaches, and to establish a common vocabulary and understanding of concepts. If we are lucky we may be able to do this without having to believe that the others are charlatans or are not doing useful work.

Ironically, in view of the original statement that elicited this tirade, some of the actual cases in which we are likely to be most in doubt about whether or not variations in traits are adaptive (derived from a history of natural selection) are not those in which the differences are environmentally induced but those in which they are heritable, in simple fashions such as when a single allele has mutated (and especially when it has not been determined if each variant is more reproductive in its bearer than would be one of its alternative states).

Returning to the example of body size variations, I conclude that Bergmann's Rule can legitimately be invoked whether interspecific or intraspecific variations are being discussed, and whether those variations, either intraspecific or interspecific, are environmentally induced or owing to genetic differences between populations. Although this may be true, it is worth noting that when variations suggesting Bergmann's Rule occur across a range extensive in relation to the vagility of the individuals of the species it is 
reasonable to expect genetic variations correlating with the phenotypic variations. There are two reasons: first, geographically different populations are not likely to benefit from being able each to deal with all of the different sets of environmental conditions they experience only separately, so are not likely to evolve environmentally induced phenotypic gradiants or alternatives in that context. Second, geographic isolation tends to result in different gene combinations, even when selection causes the different combinations to produce similar phenotypes.

\section{REFERENCES}

Alcock, J. Ardent adaptationism. Natural History 96: 4, 1987.

- Animal Behavior: A Evolutionary Approach. Fourth Edition. Sunderland, Massachusetts: Sinauer Associates, Inc., 1989.

Alexander, R.D. Arthropods. In Animal Communication, T.A. Sebeok (Ed.). Bloomington, Indiana: University of Indiana Press, 1969, pp. 167-219.

- The search for an evolutionary philosophy of man. Proceedings of the Royal Society of Victoria, Melbourne 84: 99-120, 1971.

- The evolution of social behavior. Ann. Rev. Ecol. Syst. 5: 325-383, 1974.

- Darwinism and Human Affairs. Seattle: University of Washington Press, 1979.

- The Biology of Moral Systems. Hawthorne, New York: Aldine de Gruyter, 1987a.

- Evolution: The real origin of the species. Washington Post (June 28, p. C3), 1987b).

-. Evolutionary approaches to human behavior: What does the future hold? In Human Reproductive Behaviour, L. Betzig, M. Borgerhoff Mulder, and P. Turke (Eds.). New York: Cambridge University Press, $1987 \mathrm{c}$.

- The evolution of the human psyche. In The Human Revolution, P. Mellars and C. Stringer (Eds.). University of Edinburgh Press and Princeton University Press, 1989.

- How did humans evolve? Reflections on the uniquely unique species. (Russel Lecture, March 21, 1989: University of Michigan). University of Michigan Museum of Zoology Miscellaneous Publications, in press.

, and G. Borgia. Group selection, altruism, and the levels of organization of life. Ann. Rev. Ecol. Syst. 9: 449-474, 1978.

- K.M. Noonan, and B. Crespi. The evolution of eusociality. In The Biology of the Naked Mole-Rat. P.W. Sherman, J. Jarvis, and R.D. Alexander (Eds.). Princeton University Press, 1990 , pp. 3-44.

- and D.W. Tinkle. Review of On Aggression by Konrad Lorenz and The Territorial I $^{-}$ perative by Robert Ardrey. Bioscience 18: 245-248, 1968.

Baptista, L.F. and Petrinovich L. Social interaction, sensitive phases, and the song template hypothesis in the white-crowned sparrow. Animal Behaviour 32: 172-181, 1984.

Baptista, L.F. and Petrinovich L. Song development in the white-crowned sparrow: social factors and sex differences. Animal Behaviour 34: 1359-1371, 1986.

Barkow, J.H. The distance between genes and culture. Journal of Anthropological Research 40: 367-379, 1984.

Beecher, M.D. Signature systems and kin recognition. American Zoologist 22: 475-490, 1982.

Bentley, D. and Hoy, R.R. The neurobiology of cricket song. Scientific American 231: 34-44, 1974.

Barkow, J.H. The elastic between genes and culture. Ethology and Sociobiology 10:111-1329, 1988.

Betzig, L. Mating and parenting in Darwinian perspectivc. In Human Reproductive Behavior, L. Betzig, M. Borgerhoff-Mulder, and P. Turke (Eds.). Cambridge, England: Cambridge University Press, 1988, pp. 3-20.

Betzig, L. Rethinking human ethology: a response to some recent critiques. Ethology and Sociobiology 10: 315-324, 1989. 
Bigelow, R.S. The Dawn Warriors. Man's Evolution toward Peace. Boston: Little Brown, 1969.

Blaustein, A.R. Kin recognition: phenotype matching or recognition alleles? American Naturalist 121: 749-754, 1983.

Borgerhoff-Mulder, M. Adaptation and evolutionary approaches to anthropology. Man (N.S.) 22: $25-41,1987$.

Boyd, R. and Richerson, P.J. Cultural transmission and the evolution of cooperative behavior. Human Ecology 10; 325-351, 1982.

- and Culture and the Evolutionary Process. Chicago: University of Chicago Press, 1985.

Breed, M.D. Nestmate recognition in honey bees. Animal Behaviour 31: 86-91, 1983.

Breed, M.D. and Bennett, B. Kin recognition in highly eusocial insects. In Kin Recognition in Animals, D.J.C. Fletcher and C.D. Michener (Eds.). New York: John Wiley and Sons, Ltd., 1987, pp. 243-285.

Buckle, G.R. and Greenberg, L. Nestmate recognition is sweat bees (Lasioglossum zephyrum): does an individual recognize its own odour or only odours of its nestmates? Animal Behaviour 29: 802-809, 1981.

Carneiro, R.L. A theory of the origin of the state. Science 169: 733-738, 1970.

Connor, R.C. Pseudo-reciprocity: investing in mutualism. Animal Behaviour 34: 1562-1566. 1986.

Cosmides, L. Deduction or Darwinian Algorithms? An Explanation of the Elusive Content Effect on the Wason Selection Task. Ph.D. Thesis, Harvard University. Chapter 5, Human social exchange, pp. 129-194, 1985.

Cosmides, L. The logic of social echange: Has natural selection shaped how humans reason? Studies with the Wason selection task. Cognition 31:187-276, 1989.

Cosmides, L. and Tooby, J. From evolution to behavior: evolutionary psychology as the missing link. In The Latest on the Best: Essays on Evolution and Optimality, J. Dupre (Ed.). Cambridge, Massachusetts: The MIT Press, 1987, pp. 277-306.

Cosmides, L. and Tooby, J. Evolutionary psychology and the generation of culture. Part II. Case study: A computational theory of social exchange. Ethology and Sociobiology 10: 51-97, 1988 .

Crook, J.H. and Crook, S.J. Tibetan polyandry: problems of adaptation and fitness. In Human Reproductive Behaviour, L. Betzig, M. Borgerhoff Mulder, and P. Turke (Eds.). Cambridge University Press, 1987.

Crozier, R.H. Genetic aspects of kin recognition: concepts, models, and synthesis. In Kin Recognition in Animals, D.J.C. Fletcher and C.D. Michener (Eds.). New York: John Wiley and Sons, Ltd., 1987, pp. 55-7.

Crozier, R.H. and Dix, M.W. Analysis of two genetic models for the innate components of colony odor in social insects. Behavioral Ecology and Sociobiology 4:217-224, 1979.

Darwin, C.R. On the Origin of Species. A facsimile of the first edition with an introduction by Frnst Mayr, 1967. Cambridge, Mass.: Harvard University Press, 1859.

Darwin, C.R. The Descent of Man and Selection in Relation to Sex, 2 vols. New York: Appleton, 1871.

Dawkins, R. The Selfish Gene. Oxford, England: Oxford University Press, 1976.

- The Extended Phenotype: The Gene as the Unit of Selection. San Francisco and Oxford: W.H. Freeman, 1982.

- The Blind Watchmaker. New York: W.W. Norton and Co. Inc., 1987.

Dickemann, M. Female infanticide and the reproductive strategies of stratified human societies: a preliminary model. In Evolutionary Biology and Human Social Organization: An Anthropological Perspective, N.A. Chagnon and W. Irons (Eds.). North Scituate, Mass.: Duxbury Press, 1979, pp. 321-367.

Dobzhansky, T. Discussion. In Symposium on Insect Polymorphism, J.S. Kennedy (Ed.). London: Royal Entomological Society, 1961, p. 111.

Dowsett-Lemaire, F. The imitative range of the song of the marsh warbler, Acrocephalus palustris, with special reference to imitations of African birds. Ibis 121: 453-468, 1979.

Dray, W. Laws and Explanation in History. Oxford: Oxford University Press, 1957.

Edclman, G.M. Antibody structure and molecular immunology. Science 180: 830-840, 1973.

- Neural Darwinism. The Theory of Neuronal Group Selection. New York: Basic Books, Inc., 1987. 
D.J.C. Fletcher and C.D. Michener (Eds.). Kin Recognition in Animals. New York: John Wiley and Sons, Ltd., 1987.

Flinn, M. Uterine vs agnatic kinship variability and associated cousin marriage preferences: an evolutionary biological analysis. In Natural Selection and Social Behavior, R.D. Alexander and D.W. Tinkle (Eds.). New York: Chiron Press, 1981, pp. 439-475.

and Alexander, R.D. Culture theory: the developing synthesis from biology. Human Ecology 10: 383-400, 1982.

Fodor, J.A. The Modularity of Mind. Cambridge, Mass.: MIT Press, 1983.

Gamboa, G.J., Reeve, H.K. and Pfennig, D.W. The evolution and ontogeny of nestmate recognition in social wasps. Annual Review of Entomology 1986: 431-454, 1986.

Getz, W.M. Genetically based kin recognition systems. Jour. Theoret. Biol. 92:209-226, 1981.

Getz, W.M. An analysis of learned kin recognition in Hymenoptera. Journal of Theoretical Biology 99: 585-597, 1982.

Getz, W.M. In Kin Recognition. P.G. Hepper (Ed.). Cambridge University Press, in press.

Getz, W.M. and Smith, K.B. Genetic kin recognition: honeybees discriminate between fulland half- sisters. Nature 302: 147-148, 1983.

Ghiselin, M.T. Darwin and evolutionary psychology. Science 179: 964-968, 1973.

Gleitman, L.R. Biological predispositions to language learning. In The Biology of Learning. P. Marler and H.S. Terrace (Eds.). Berlin: Springer-Verlag, 1984, pp. 553-584.

Gould, J.L. Ethology: The Mechanisms and Evolution of Behavior. New York: Norton, 1982. The biology of learning. Ann. Rev. Psychol. 37: 163-192, 1986.

Gould, S.J. Hyena myths and realities. Natural History 90: 16-24, 1981.

- Freudian slip. Natural History 96: 14-21, 1987.

and Lewontin, R.W. The spandrels of San Marco and the Panglossian paradigm: a critique of the adaptationist programme, Proceedings of the Royal Sociery of London B 205: 581-598, 1979.

Grau, J.H. Kin recognition in white-footed deermice (Peromyscus leucopus). Animal Behaviour 30: $497-505,1982$

Greenberg, L. Genetic component of bee odor in kin recognition. Science 206: 1095-1097, 1979.

Hailman, J.P. Bee-dancing and evolutionary epistemology. American Naturalist 111: 187-189, 1977.

Hamilton, W.D. The genetical evolution of social behaviour. I, II. Journal of Theoretical Biology 7: $1-52,1964$.

- Geometry for the selfish herd. Journal of Theoretical Biology 31: 295-311, 1971.

Innate social aptitudes of man: an approach from evolutionary genetics. In Biosocial Anthropology, R. Fox (Ed.). New York: Wiley, 1975, pp. 135-155.

- Discriminating nepotism: expectable, common, overlooked. In Kin Recognition in Animals, D.J.C. Fletcher and C.D. Michener (Eds.). New York: John Wiley and sons, Ltd., 1987, pp. 417-438.

Hankin, J. and Sherman, P.W. Multiple paternity in Belding's ground squirrel litters. Science 212: 351-353, 1981 .

Hepper, P.G. (Ed.). Kin Recognition. Cambridge University Press, in press.

Herrnstein, R.J. The evolution of behaviorism. American Psychologist an: 593-603, 19787.

R.A. Hinde and J. Stevenson-Hinde (Eds.). Constraints on Learning: Limitations and Predispositions. New York: Academic Press, 1973.

Holldobler, B. and Michener, C.D. Mechanisms of identification and discrimination in social Hymenoptera. In Evolution of Social Behavior: Hypotheses and Empirical Tests, $\mathrm{H}$. Markl (Ed.). Weinheim: Verlag Chemic, 1980, pp. 35-58.

Holmes, W.G. Ontogeny of dam-young recognition in captive Belding's ground squirrels (Spermophilus beldingi). Journal of Comparative Psychology 98: 246-256, 1984.

Holmes, W.G. Kin recognition by phenotype matching in female Belding's ground squirrels. Animal Behaviour 34: 38-47, 1986a.

- Identification of paternal half-siblings by captive Belding's ground squirrels. Animal Behaviour 34: 321-327, 1986b.

- Kinship and the development of social preferences. In Handbook of Behavioral Neurobiology. Volume 9. Developmental Psychobiology and Behavioral Ecology. E.M. Blass (Ed.). New York: Plenum Press, 1988, pp. 289-413.

Holmes, W.G. and Sherman, P.W. The ontogeny of kin recognition in two species of ground squirrels. American Zoologist 22: 491-517, 1982. 
Holmes, W. and Sherman, P.W. Kin recognition in animals. Amer. Sci. 71: 46-55, 1983.

Humphrey, N.K. The social function of intellect. In Growing Points in Ethology, P.P.G. Bateson and R.A. Hinde (Eds.). London: Cambridge University Press, 1976.

Nature's psychologists. New Scientist 78: 900-903, 1978.

Nature's psychologists. In: Consciousness and the Physical World. B. Josephson and B.S. Ramchandra (Eds.). New York: Pergamon, 1979, pp. 57-75.

- Consciousness Regained: Chapters in the Development of Mind. Oxford: Oxford University Press, 1983.

- The Inner Eye. London: Faber and Faber, 1986.

- The uses of consciousness. Fifty-Seventh James Arthur Lecture on the Evolution of the Human Brain. New York: American Museum of Natural History, pp. 1-22, 1987.

Jacobson, M. Developmental Neurobiology. New York: Plenum Press, 1978.

Jaynes, J. The Origin of Consciousness in the Breakdown of the Bicameral Mind. Boston: Houghton Mifflin, 1977.

Johnston, T.D. Selective costs and benefits in the evolution of learning. Advances in the Study of Behavior 12: 65-106, 1982a.

Learning and the evolution of development systems. In Learning, Development, and Culture: Essays in Evolutionary Epistemology, H.C. Plotkin (Ed.). New York: Wiley. 1982b, pp. 411-422.

Kareem, A.M. and Barnard, C.J. The importance of kinship and familarity in social interactions between mice. Animal Behaviour 30: 594-601, 1982.

Kennedy, J.S. Phase transformation in locust biology. Biological Review's 31: 349-370, 1956.

Key, K.H.L. A critique on the phase theory of locusts. Quarterly Review of Biology 25:363$407,1950$.

Keith, A. A New Theory of Human Evolution. New York: Philosophy Library, 1949.

Kihlstrom, J.F. The cognitive unconscious. Science 237: 1445-1452, 1987.

Kitcher, P. Vaulting Ambition. MIT Press, 1987a.

- Confessions of a curmudgeon. Bchavioral and Brain Sciences 10: 89-99, $1987 \mathrm{~b}$.

Konishi, M. and Nottebohm, F. Experimental studies in the ontogeny of avian vocalizations. In Bird Vocalizations, R.A. Hinde (Ed.). Cambridge: Cambridge University Press, 1969, pp. 29-48.

Kroodsma, D.E. and Pickert, R. Repertoire size, auditory templates, and selective vocal learning in songbirds. Animal Behaviour 32: 395-399, 1984.

Kurland, J. Paternity, mother's brother, and human sociality. In Evolutionary Biology and Human Social Behavior: An Anthropological Perspective, N.A. Chagnon and W.G. Irons (Eds.). North Scituate, Mass.: Duxbury Press, 1979, pp. 145-180.

Lacy, R.C. and Sherman, P.W. Kin recognition by phenotype matching. Amer. Nat. 121: 489512, 1983.

Linsenmair, K.E. Kin recognition in subsocial arthropods, in particular in the desert isopod Hemilepistus reaumuri. In Kin Recognition in Animals, D.J.C. Fletcher and C.D. Michener (Eds.). New York: John Wiley and Sons, Ltd., 1987, pp. 121-208.

Lumsden, C.J., and Wilson, E.O. Genes, Mind, and Culture: The Coevolutionary Process. Cambridge, Mass.: Harvard University Press, 1981.

P. Marler and H. Terrace (Eds.). The Biology of Learning. Berlin: Spring-Verlag, 1984.

Maynard Smith, J. The Problems of Biology. Oxford: Oxford University Press, 1986.

May, R.M. and Robertson, M. Just so stories and cautionary tales. Nature 286: 327-329, 1980.

Mintzer, A. Nestmate recognition and incompatibility between colonies of the acacia-ant Pseudomyrmex ferruginea. Behavioral Ecology and Sociobiology 10: 165-168, 1982.

O'Hara, R.J. Homage to Clio, or, toward an historical philosophy for evolutionary biology. Systematic Zoology 37: 142-155, 1988.

Otte, D. Effects and functions in the evolution of signaling systems. Annual Review of Ecology and Systematics 5: 385-417, 1974.

Pakstis, A.S., Scarr-Salapatek, S., Elston, R.C., and Siervogel, R. Genetic contributions to morphological and behavioral similarities among sibs and dizygotic twins: linkages and allelic differences. Social Biology 19: 185-192, 1972.

Queller, D. Kin selection and frequency-dependence: a game-theoretic approach. Biol. Journal of the Linnaean Society 23: 133-143, 1984.

Reeve, H.K. The Evolution of Conspecific Acceptance Thresholds. Am. Naturalist 133: 407$435,1989$. 
Ridley, M. and Grafen, A. Are green beard genes outlaws? Animal Behaviour 29: 954-955, 1981.

Rose, M. The mental arms race amplifier. Human Ecology 8:285-293, 1980.

- Hominid evolution and social science. Journal of Social and Biological Structures 6:29$36,1983$.

Rozin, $P$. The evolution of intelligence and access to the cognitive unconscious. In Progress in Psychobiology and Physiological Psychology, J.M. Sprague and A.N. Epstein (Eds.). New York: Academic Press, 1976.

Salzen, E.A. and Cornell, J.M. Self-perception and species recognition in birds. Behaviour 30: 44-65, 1968.

Schwartz B. On going back to nature: a review of Seligman and Hager's Biological Boundaries of Learning. Journal of the Experimental Analysis of Behavior 21: 183-198, 1974.

Seligman, M.E.P. On the generality of the laws of learning. Psychol. Rev. 77: 406, 1970.

— and J.L. Hager. (Eds.). Biological Boundaries of Learning. New York: Appleton-CenturyCrofts.

Shepard, R.N. Ecological constraints on internal representation: resonant kinematics of perceiving, imagining, thinking, and dreaming. Psychological Review 91: 417-447, 1984.

Sherman, P.W. The limits of ground squirrel nepotism. In Sociobiology: Beyond Nature and Nurture? G.W. Barlow and J. Silverberg (Eds.). AAAS Selected Symposium 35. Boulder, Colorado: Westview Press, 1980, pp. 505-544.

Sherman, P.W. The levels of analysis. Animal Behaviour 36: 616-618, 1988.

Sherman, P.W. and Holmes, W.G. Kin recognition: issues and evidence. In Experimental Behavioral Ecology and Sociobiology, B. Holldobler and M. Lindauer (Eds.). Sunderland, Mass., 1985, pp. 437-460.

Slater, P.J.B. Bird song learning: causes and consequences. Ethology, Ecology, and Evolution 1: $19-46,1989$.

Symons, D. If we're all Darwinians, what's the fuss about? In Sociobiology and Psychology. C. Crawford, M. Smith, and D. Krebs (Eds.). Hillsdale, New Jersey: Erlbaum Publishers, 1987.

Symons, D. A critique of Darwinian anthropology. Ethology and Sociobiology 10: 131-144, 1989.

Tierney, A.J. The evolution of learned and innate behavior: contributions from genetics and neurobiology to a theory of behavioral evolution. Animal Learning and Behavior 14: $339-348,1986$.

Tooby, J. The emergence of evolutionary psychology. In Emerging Syntheses in Science. D. Pines (Ed.). Santa Fe, New Mexico: Santa Fe Institute, 1985.

Tooby, J. and Cosmides, L. Evolutionary psychology and the generation of culture. Part $\mathbf{l}$. Theoretical considerations. Ethology and Sociobiology 10: 29-549, 1988.

Trivers, R.L. The evolution of reciprocal altruism. Quart. Rev. Biol. 46: 35-57, 1971.

-. Social Evolution. Menlo Park, Calif.: Benjamin/Cummins, 1985.

Turke, P. Evolution and the demand for children. Population and Development Review 15: 61 90,1989

Turke, P.W. and Betzig, L. L. Those who can do: wealth, status, and reproductive success on Ifaluk. Ethology and Sociobiology 6:79-87, 1985.

Velutino, F.R., Dyslexia. Scientific American 256: 34-41, 1987.

Vidal, J.M. "Auto-imprinting": effects of prolonged isolation on domestic cocks. J. Comp. Physiol. Psych. 96: 256-267, 1982.

Waddington, C.H. Principles of Embryology. New York: Macmillan, pp. 10-14, 1956.

Waldman, B. Sibling recognition in toad tadpoles: the role of experience. Zeitschrift fur Tierpsychologie 56: 341-358, 1981.

Waldman, B. Chemical ecology of kin recognition in anuran amphibians. In Ecology, Evolution, and Comparative Biology, D. Duvall, D. Muller-Schwarze, and R.M. Silverstein (Eds.). New York: Plenum Press, 1986, pp. 1-18.

Waldman, B. The ecology of kin recognition. Annual Review of Ecology and Systematics 19, 1988.

Waldman, B., Frumhoff, P.C. and Sherman, P.W. Problems of kin recognition. Trends in Ecology and Evolution 3: 8-13, 1988.

Wallace, B. Topics in Population Genetics. New York: W.W. Norton and Co., Inc., 1968. 
Wells, P.A. Kin recognition in humans. In Kin Recognition in Animals, D.J.C. Fletcher and C.D. Michener (Eds.). New York: John Wiley and Sons, Ltd., 1987, pp. 395-415.

West, M.J. and King, A.P. Social guidance of vocal learning by female cowbirds: validating its functional significance. Zeitschrift fur Tierpsychologie 70: 225-235, 1985.

West Eberhard, M.J. Flexible strategy and social evolution. In Animal Societies: Theories and Facts, Y. Ito, J.L. Brown, and J. Kikkawa (Eds.). Tokyo: Japan Scientific Society Press, 1987, pp. 35-51.

Williams, G.C. Adaptation and Natural Selection: A Critique of some Current Evolutionary Thought. Princeton, New Jersey: Princeton University Press, 1966.

Williams, G.C. In defense of reductionism in evolution. Oxford Surveys in Biology 2:1-27, 1987.

Wilson, E.O. The Insect Societies. Cambridge, Mass.: Harvard University Press, 1971.

Wilson, E.O. Kin recognition: an introductory synopsis. In Kin Recognition in Animuls, D.J.C. Fletcher and C.D. Michener (Eds.). New York: John Wiley and Sons, Ltd., 1987, pp. $7-18$.

Wu, H.M.H., Holmes, W.G., Medina, S.R., and Sackett, G.P. Kin preference in infant Macaca nemestrina. Nature 285: 225-227, 1980.

Wynn, T. Tools and the evolution of human intelligence. In Machiavellian Intelligence. Social Expertise and the Evolution of Intellect in Monkeys, Apes, and Humans, R.W. Byrne and A. Whiten (Eds.). Oxford: Clarendon Press, 1988, pp. 271-284.

Yamazaki, K., Beauchamp, G.K., Kupniewski, D., Bard, J., Thomas, L., and Boyse, E.A. Familial imprinting determines H-2 Selective mating preferences. Science 240: 1331$1332,1988$. 